\title{
Small-Chamber Measurements of Chemical-Specific Emission Factors for Drywall
}

\author{
Randy Maddalena ${ }^{1}$, Marion Russell ${ }^{1}$, Moya Melody $^{2}$, \\ and Michael G. Apte ${ }^{1}$ \\ ${ }^{1}$ Environmental Energy Technologies Division \\ Indoor Environment Department \\ Lawrence Berkeley National Laboratory \\ Berkeley, CA 94720 \\ ${ }^{2}$ Freelance Editor/Writer, Santa Fe NM \\ Under Subcontract Number 6938608 \\ to Lawrence Berkeley National Laboratory.
}

June 2010

This report was prepared as a result of work sponsored by the U.S. Consumer Product Safety Commission (CPSC) under Federal Interagency Agreement CPSC1090013 and by the U.S. Department of Energy under Contract No. DE-AC02-05CH11231. 


\section{ERNEST ORLANDO LAWRENCE BERKELEY NATIONAL LABORATORY}

\section{SMALl-Chamber Measurements OF CHEMiCAL- SPECIFIC EMISSION FACTORS FOR DRYWALL}

Randy Maddalena, Marion Russell, Moya Melody, and Michael G. Apte

\section{Environmental Energy Technologies Division}

March 2010

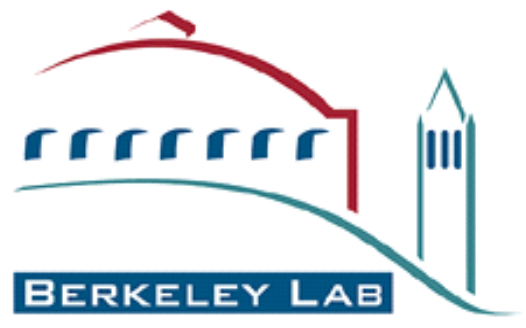





\section{DISCLAIMER}

This document was prepared as an account of work sponsored by the United States Government. While this document is believed to contain correct information, neither the United States Government nor any agency thereof, nor The Regents of the University of California, nor any of their employees, makes any warranty, express or implied, or assumes any legal responsibility for the accuracy, completeness, or usefulness of any information, apparatus, product, or process disclosed, or represents that its use would not infringe privately owned rights. Reference herein to any specific commercial product, process, or service by its trade name, trademark, manufacturer, or otherwise, does not necessarily constitute or imply its endorsement, recommendation, or favoring by the United States Government or any agency thereof, or The Regents of the University of California. The views and opinions of authors expressed herein do not necessarily state or reflect those of the United States Government or any agency thereof, or The Regents of the University of California. 


\title{
Small-Chamber Measurements of Chemical-Specific Emission Factors for Drywall
}

\author{
Randy Maddalena ${ }^{1}$, Marion Russell ${ }^{1}$, Moya Melody ${ }^{2}$, \\ and Michael G. Apte ${ }^{1}$ \\ 1. Indoor Environment Department \\ Environmental Energy Technologies Division \\ Lawrence Berkeley National Laboratory \\ Berkeley, CA 94720 \\ 2. Freelance Editor/Writer, Santa Fe NM \\ Under Subcontract Number 6938608 \\ to Lawrence Berkeley National Laboratory.
}

Prepared for:

Joanna M. Matheson, Ph.D.

Toxicologist

U.S. Consumer Product Safety Commission

Health Sciences Division

4330 East West Highway

Bethesda, MD 20814

June 2010 
This report was prepared as a result of work sponsored by the U.S. Consumer Product Safety Commission (CPSC) under Federal Interagency Agreement CPSC1090013 and by the U.S. Department of Energy under Contract No. DEAC02-05CH11231. The authors are grateful to Hugo Destaillats for technical assistance and a thorough review of this report. We also thank Tosh Hotchi for setup of the conditioning chambers and metal fabrication, and Doug Sullivan for assistance with the emission chamber. 

This page is intentionally blank. 


\begin{abstract}
Imported drywall installed in U.S. homes is suspected of being a source of odorous and potentially corrosive indoor pollutants. To support an investigation of those building materials by the Consumer Products Safety Commission (CPSC), Lawrence Berkeley National Laboratory (LBNL) measured chemical-specific emission factors for 30 samples of drywall materials. Emission factors are reported for 75 chemicals and 30 different drywall samples encompassing both domestic and imported stock and incorporating natural, synthetic, or mixed gypsum core material. CPSC supplied all drywall materials. First the drywall samples were isolated and conditioned in dedicated chambers, then they were transferred to small chambers where emission testing was performed. Four sampling and analysis methods were utilized to assess (1) volatile organic compounds, (2) low molecular weight carbonyls, (3) volatile sulfur compounds, and (4) reactive sulfur gases. LBNL developed a new method that combines the use of solid phase microextraction (SPME) with small emission chambers to measure the reactive sulfur gases, then extended that technique to measure the full suite of volatile sulfur compounds. The testing procedure and analysis methods are described in detail herein. Emission factors were measured under a single set of controlled environmental conditions. The results are compared graphically for each method and in detailed tables for use in estimating indoor exposure concentrations.
\end{abstract}




\section{TABLE OF CONTENTS}

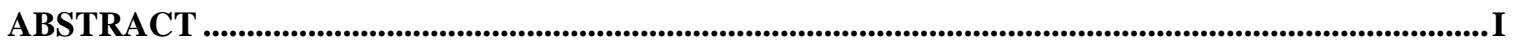

TABLE OF CONTENTS ........................................................................................................................... II

LIST OF FIGURES...........................................................................................................................................III

LIST OF TABLES..................................................................................................................................

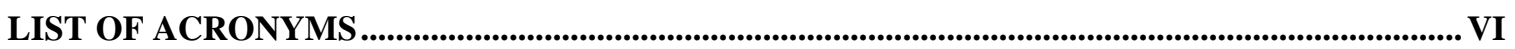

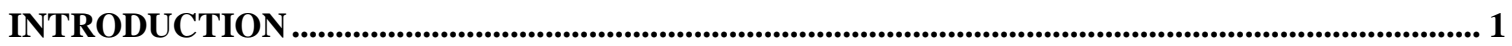

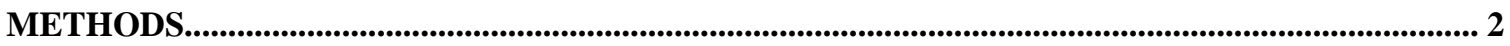

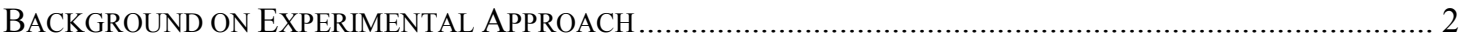

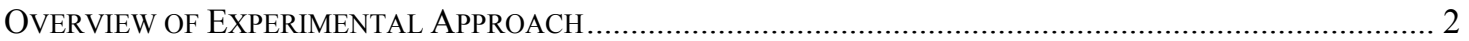

MATERIAL HANDLING AND PREPARATION .............................................................................. 3

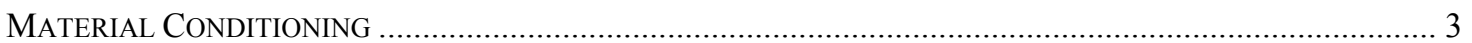

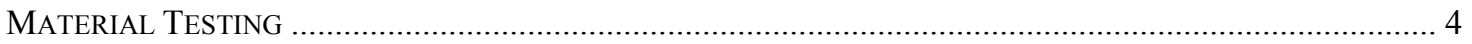

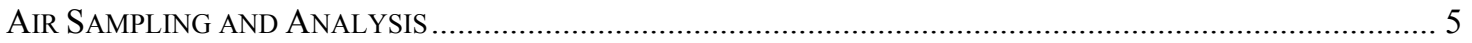

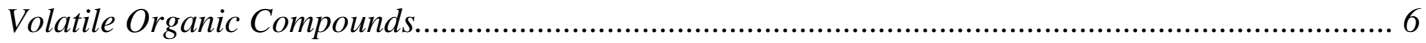

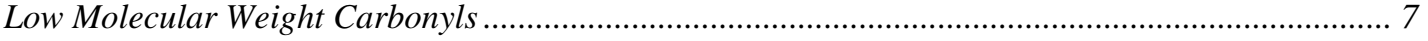

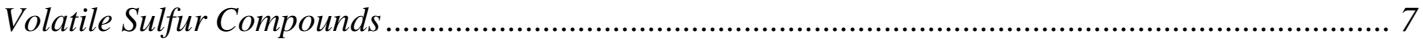

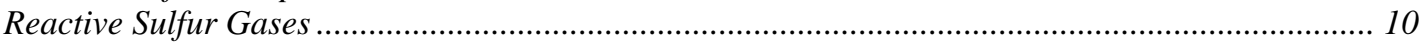

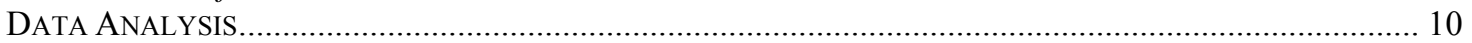

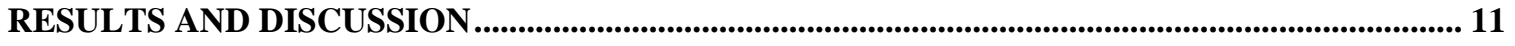

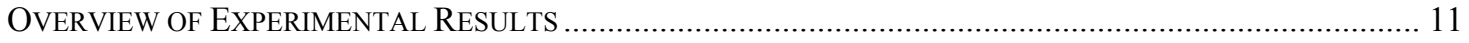

EMISSIONS OF VOLATILE ORGANIC COMPOUNDS ................................................................... 11

EMISSIONS OF LOW MOLECULAR WEIGHT CARBONYLS...................................................................... 13

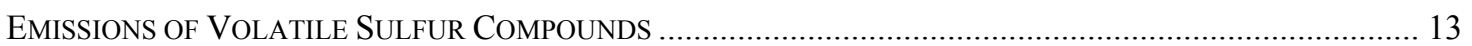

EMISSIONS OF REACTIVE SULFUR GASES ............................................................................ 15

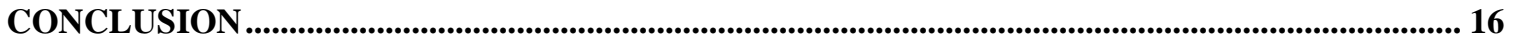

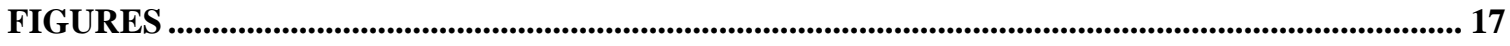

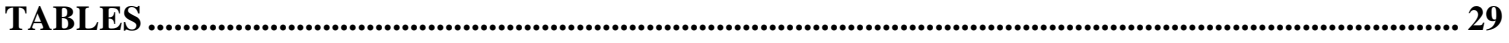

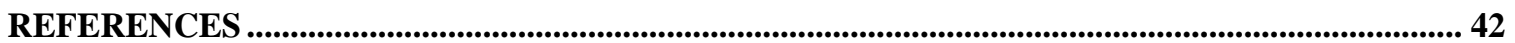




\section{LIST OF FIGURES}

Figure 1: Relationships between chromatographic retention times using the method for volatile sulfur chemicals and the number of carbon atoms in sulfides (solid diamonds) or symmetric disulfides (solid triangles).

Figure 2: During development of the solid-phase microextraction (SPME) method the sampling rate was evaluated to determine the optimum sampling time. Fifty minutes was selected as an appropriate sample time to provide adequate response for a range of chemicals within the time constraints of the analysis by gas chromatography. This figure also illustrates the difference in partitioning into the SPME fiber for the sulfur gases and shows that as the molecular size increases, the uptake rate becomes linear over the full 50-minute sampling period.

Figure 3: Total ion chromatograms for volatile organic chemicals are compared for the first 17 samples tested. The peak at about 28 minutes is the internal standard added to each sample before analysis. The larger peak after 50 minutes represents butylated hydroxytoluene. Other chemicals were identified at very low concentrations, as shown in the chromatogram in Figure 4 and as reported in Table 1

Figure 4: This figure zooms in on the chromatogram from Figure 3 at the peak height (yaxis) to show the chromatographic fingerprint of the lower-concentration volatile organic chemicals in the emission stream for sample 7339. Only a few of peaks (chemicals) exceed the approximate limit of quantitation of about $1 \mathrm{ng}$, representing

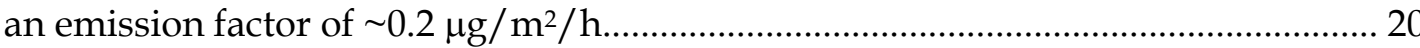

Figure 5: A compilation of total emissions of volatile organic chemicals from the tested samples. The CPSC material tracking number is listed across the category axis. The legend lists the specific chemicals in the order in which they are stacked. The chemicals having "TIC" at the end of their names were quantified as toluene based on their total ion chromatogram.

Figure 6: The sum of low molecular weight carbonyl emissions from the tested samples. The CPSC material tracking numbers are listed across the category axis. The legend lists the specific chemicals in the order in which they are stacked. Samples reported to the left of the vertical line were measured at a temperature of $38 \mathrm{C}^{\circ}( \pm 1 \%$ coefficient of variation) and relative humidity $(\mathrm{RH})$ of $69 \%( \pm 7 \%)$. The values to the right of the vertical line were measured at $25 \mathrm{C}^{\circ}( \pm 1 \%)$ and $49 \% \mathrm{RH}( \pm 3 \%)$. 22

Figure 7: Comparison of sulfur gas emission fingerprints for the first 17 samples tested. The chromatograms are derived from 50-minute solid-phase microextraction (SPME) samples quantified using the sulfur chemiluminescence (SCD). Thus although all sulfur gases emitted from the drywall samples (RSGs and VSCs) are shown, the response area of the peaks are not proportional to the relative strength of the individual chemical emissions. The RSGs are represented by the peaks eluting in the first 8 minutes, and the VSCs are represented by the remaining peaks. The 
last four digits of the CPSC tracking number are listed down the right side of the figure. The chromatograms are sorted from top to bottom based on descending total sulfur gas emissions. The possible unidentified SPME artifact is discussed in the body of the report.

Figure 8: A single chromatogram from one of the samples listed in the previous figure but using the sampling method for volatile sulfur chemicals, not the SPME method. The grey line shows the approximate limit of quantification for this method. In this figure, given the equimolar response of the detector, the peak areas (and heights) are approximately proportional to the sulfur gas emission rate in terms of the mass of sulfur.

Figure 9: The sum of volatile sulfur (VSC) emissions from the tested samples. The CPSC material tracking number is listed across the category axis, and the legend lists the specific chemicals in the order in which they are stacked. The number in parenthesis above each column indicates the sampling and analysis method used for that sample where (1) indicates that both the SPME-GC/SCD and TD-GC/SCD method were used; (2) indicates that the TD-GC/SCD method was used; and (3) indicates that the SPME-GC/SCD method was used.. Note that the emission factors for the VSCs are reported in units of $\mathrm{ng} / \mathrm{m}^{2} / \mathrm{h}$. The 12 chemicals listed capture $>80 \%$ of the chemical mass in the emission stream. The segment in the stacked columns labeled "other identified $(\mathrm{n}<30)$ " includes the sum of all remaining identified chemicals in the emissions stream. The top segment includes all remaining unidentified chemicals.

Figure 10: The relationship between the derived sample volume for a 50-minute SPME sample collected from the small chamber under standard conditions is shown across the range of retention times for the measured volatile sulfur chemicals (VSCs) in the emission stream. The data presented here represent 70 sample pairs from five independent measurements collected from two different samples. The line indicating a decreasing trend in sample rate with increasing retention time can be explained by a decrease in chemical diffusivity with increasing molecular size. Because the trend is not significant over the limited range in which most of the measured VSCs elute (between 17 and 24 minutes), the data were used to estimate an average SPME sampling rate for all VSCs.

Figure 11: A zoomed region for material 7339 from Figure 7 with each peak identified. Significant tailing in the early eluting chemicals required a tangent skim method for peak integration to resolve the first three chemicals. The baselines for carbonyl sulfide and sulfur dioxide were drawn first as shown to estimate the peak area for each chemical, then a second baseline encompassing all three peaks was drawn and the area for hydrogen sulfide was determined by subtraction

Figure 12: The sum of reactive sulfur gases. The CPSC material tracking number is listed across the category axis, and the legend lists the specific chemicals in the order in which they are stacked. The units are in $\mu \mathrm{g} / \mathrm{m}^{2} / \mathrm{h}$, and actual values are listed in Table 3. 


\section{LIST OF TABLES}

Table 1: Emission factors $\left(\mu \mathrm{g} / \mathrm{m}^{2} / \mathrm{h}\right)$ for volatile organic chemicals and aldehydes........ 29

Table 2: Emission factors $\left(\mathrm{ng} / \mathrm{m}^{2} / \mathrm{h}\right.$ ) for volatile sulfur chemicals .................................... 35

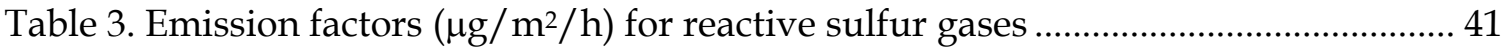




\section{LIST OF ACRONYMS}

$\begin{array}{ll}\text { ACH } & \text { air changes per hour } \\ \text { CPSC } & \text { U.S. Consumer Product Safety Commission } \\ \text { GC } & \text { gas chromatography } \\ \text { HPLC } & \text { high-performance liquid chromatography } \\ \text { LBNL } & \text { Lawrence Berkeley National Laboratory } \\ \text { LOD } & \text { limit of detection } \\ \text { LOQ } & \text { limit of quantification } \\ \text { MS } & \text { mass spectrometry } \\ \text { MSD } & \text { mass spectrometry detector } \\ \text { PDMS } & \text { polydimethylsiloxane } \\ \text { RH } & \text { relative humidity } \\ \text { RSGs } & \text { reactive sulfur gases } \\ \text { SCD } & \text { sulfur chemiluminescence detector } \\ \text { SPME } & \text { solid-phase microextraction } \\ \text { T } & \text { temperature } \\ \text { TD } & \text { thermo desorption } \\ \text { TDS } & \text { thermal desorption system } \\ \text { TIC } & \text { total ion chromatogram } \\ \text { UV } & \text { ultraviolet } \\ \text { VOCs } & \text { volatile organic compounds } \\ \text { VSCs } & \text { volatile sulfur compounds }\end{array}$




\section{INTRODUCTION}

Gypsum is a mineral that is used widely to manufacture drywall and plaster for homes and commercial buildings constructed in the United States and worldwide (Founie, 2003). Gypsum, or calcium sulfate dihydrate $\left(\mathrm{CaSO}_{4} \bullet 2 \mathrm{H}_{2} 0\right)$, is either mined or collected as a byproduct of flue-gas desulfurization systems installed at coal fired power plants. The production of drywall follows several steps where the raw gypsum material is passed through a kiln to produce a partially dehydrated form that can be ground to a powder form called plaster of Paris. The plaster is mixed with additives and water to create a slurry that is poured and sandwiched between two continuous sheets of paper. The sheets are cut to the desired length and dried by passing through an oven.

Imported (Chinese) drywall installed in U.S. homes is suspected of being a source of odorous and potentially corrosive indoor pollutants. The U.S. Consumer Product Safety Commission (CPSC) has received reports of possible corrosion-related problems with heating, ventilation, and air conditioning systems; electric appliances; electronic devices; smoke alarms; security systems; and electrical switches in affected homes. Residents have reported a spectrum of health concerns, including recurrent headaches, irritated and itchy eyes and skin, difficulty in breathing, persistent coughs, runny noses, sinus infections and congestion, sore throats, frequent nosebleeds, and asthma attacks.

The biological conversion of sulfate in gypsum drywall is known to produce hydrogen sulfide in construction and demolition landfills (Lee et al., 2006). Sulfur in ambient air in industrial areas is associated with both odor and health problems (Kim et al., 2006a and b; Pal et al., 2009). Hydrogen sulfide and carbonyl sulfide have also been identified as possible synergistic factors in the tarnishing of silver items in museums (Ankersmit et al., 2005).

CPSC's investigation of drywall incorporates three parallel tracks: (1) evaluating the relationship between the drywall and reported health symptoms; (2) evaluating the relationship between the drywall and electrical and fire safety issues in affected homes; and (3) tracing the origin and the distribution of the drywall. To assess the impact on human health and to support testing for electrical and fire safety, the CPSC has initiated a series of tests that include laboratory elemental characterization of drywall, characterization of chemical emissions, and in-home air sampling.

The chemical emission testing is being conducted at Lawrence Berkeley National Laboratory (LBNL). The goal of the LBNL testing at is to identify the individual chemical constituents in the emission stream from drywall samples and determine chemical-specific emission rates for a range of material samples from both domestic and imported drywall. The primary focus is on volatile sulfur chemicals (VSCs), but also considered are volatile organic chemicals (VOCs) and low molecular weight carbonyls, including formaldehyde. Emission rates are derived and reported in terms of standard emission factors using units of chemical mass released per unit area of emitting surface per unit time as measured at constant environmental temperature, relative humidity, and ventilation rate.

This report provides details of the procedure LBNL utilized to measure chemical-specific emission factors for drywall using small, well-mixed, continuous-flow emission 
chambers. Testing results are provided for 30 samples. This investigation was conducted under one set of environmental conditions $\left(25^{\circ} \mathrm{C}, 50 \%\right.$ relative humidity, and an areaspecific ventilation rate of $\sim 1.5$ cubic meters per square meter $\left[\mathrm{m}^{3} / \mathrm{m}^{2}\right]$ of emitting surface per hour). Measurements were not taken under the varied environmental conditions that may exist in homes or other built structures, including various combinations of temperature, humidity, and ventilation rate but the results reported here provide a baseline value for emission factors for a range of both imported and domestic drywall samples.

\section{METHODS}

This section describes LBNL's experimental methods, including an overview and background for the approach; methods used for handling, preparing, conditioning, and testing the samples; air sampling and analysis; and data analysis.

\section{Background on Experimental Approach}

Efforts to measure sulfur compounds in air have included both indoor and outdoor environments using real-time sulfur gas analyzers, passive samplers or active samples collected in containers or focused on sorbent material and analyzed using a variety of laboratory based analytical instruments. In addition to the research noted above in the introduction, studies have measured reduced or volatile sulfur compounds in ambient air near (1) industrial areas (Pal et al., 2009; Kim et al., 2006a and b); (2) sewage treatment plants (Ras et al., 2008a and b); and (3) animal feeding operations (Trabue et al., 2008; Ni et al., 2000). Unlike LBNL's small-chamber study of individual drywall samples, such studies have not measured sulfur components emitted directly by specific materials. Controlled laboratory emission chambers are needed to collect the analytes directly from the material of interest to quantify material specific emission factors. The analytical methods LBNL developed to work with the emission testing chambers are similar to and based on those used to analyze samples of ambient air for sulfur compounds, including gas chromatography, mass spectrometry, solid phase microextraction, and sulfur chemiluminescence detection. The LBNL team found, however, that the methods for ambient air samples described in the literature had to be modified to meet the needs for direct emission testing particularly for the reactive sulfur gases. The approach developed by LBNL for measuring the reactive sulfur gases combines the use of solid phase microextraction (SPME) with small emission testing chambers to measure the reactive sulfur gases. The approach is also adapted to measure the full suite of volatile sulfur chemicals in emission chambers for future work.

\section{Overview of Experimental Approach}

The CPSC provided LBNL with all materials for testing. Before testing began, individual pieces for testing were cut from the sample provided and installed in stainless steel conditioning chambers that were supplied with a continuous stream of clean, humidified air. The samples were isolated continuously in either the conditioning chambers or test chambers until emissions measurements were completed. The emissions testing was performed in small chambers housed inside a larger controlled-environment chamber. A continuous supply of clean, humidified air was passed through each chamber and the outflow was exhausted to a fume hood. Air samples were collected directly from the 
chambers after concentrations achieved steady state where the concentration of compounds in the chamber were not changing with time. The measurements collected from the chambers were analyzed using a range of methods depending on the target chemical class. The measured concentration for each chemical was then used along with known ventilation rates, chamber volume, and projected material surface area to calculate the material-specific emission factor for each chemical. Details of the approach are provided below.

\section{Material Handling and Preparation}

CPSC staff collected drywall samples from manufacturers, drywall suppliers, and storage warehouses. Samples were cut into approximately one-square-foot $\left(0.09-\mathrm{m}^{2}\right)$ pieces, heatsealed individually in Tedlar bags, and assigned a unique identification number. Tedlar bags have been found to provide suitable storage even for air samples collected for analysis of volatile sulfur compounds (Mochalski et al., 2009). An identification label typically was affixed to the outside of each bag. For some samples, the labels were applied directly to the face of the material; if so, the labeled part of the drywall sample was not included in the emissions testing. The individually bagged material samples were boxed and shipped to LBNL along with a list of identification numbers. When the samples arrived at LBNL, they were removed from the box, inspected, then returned to the shipping box and stored at room temperature until testing began.

In preparation for testing, the samples were removed from their individual sealed bags. A 6-inch $(15.25-\mathrm{cm})$ square was cut from each piece by scoring the facing paper using a straight edge and clean razor knife, then breaking the material along the scored line. The raw edges of the drywall were then filed smooth using a drywall rasp, and a small amount of gypsum material was collected and archived for each sample. The raw edges were then sealed with aluminum tape low in volatile organic compounds (VOCs), leaving both the front and back paper faces of the drywall exposed. Typically, only a single face of a material is tested for emissions to determine release into the living space of a structure but in this case it was also important to know what emissions into the wall space might be to assess corrosion. The resulting measurements using this approach provide an average emission rate for the front and back face of the material. The exposed paper faces were unfinished; i.e., no paint or plaster was applied to the drywall before testing. After the total exposed area of each sample was measured, it was placed in an individual conditioning chamber where it remained until testing.

\section{Material Conditioning}

The drywall materials collected for this study represented either domestic or imported stock. Records documenting the manufacture date and/or storage history were not available. Therefore, it was important to fully condition the samples to allow potential contaminants that were not indigenous to the material to off-gas before testing. Further, it was important to provide a clean and controlled environment to allow the samples to equilibrate with the test conditions, particularly the target humidity used in testing, before transferring the samples to the test chamber.

Sixteen individual conditioning chambers were constructed using 6-liter (L) air-tight stainless steel food-grade containers (www.noplastic.ca). Each container was plumbed with a dedicated inlet and outlet line and mounted on a panel for easy access. To eliminate interference by atmospheric oxidants (Pandey and Kim, 2009), dry house air 
was passed through an activated carbon filter followed by a HEPA filter; then part of the air stream was passed through a bubbler containing deionized water. A small amount of activated carbon was placed in the bubbler reservoir. The wet and dry air streams were remixed to produce the desired relative humidity and avoid problems associated with high humidity (Pandey and Kim, 2009). The humidified air was delivered at approximately 250 cubic centimeters per minute (cc/min; 1.4 air changes per hour $[\mathrm{ACH}])$ to each chamber using flow-control valves and taper-tube flow meters.

Initial screening experiments identified several cyclic siloxanes ${ }^{1}$ at elevated and increasing levels in the conditioned materials. The silicone gaskets in the lid of the conditioning chambers were suspected as the source of the cyclic siloxanes, so the lids were lined with Teflon film for all subsequent experiments. Evaluation of Teflon indicates that it does not create interference with the accurate measurement of reduced sulfur compounds from material samples (Mochalski, 2009; Kim et al., 2006a), and indeed no further siloxane contamination was detected in the conditioning system.

Drywall samples were conditioned for a minimum of one week before initial emissions testing, but conditioning and testing continued for several months while analytical methods were optimized. Conditioning time was recorded for the individual samples as they were tested.

\section{Material Testing}

Emissions testing approach using small emission chambers generally follows ASTM Standard Guide D-5116-97 (ASTM International, 2002) and California Specification 01350 (CDHS, 2004). The approach has been used for a wide range of building materials measuring both VOCs and carbonyls as described previously (Maddalena et.al., 2009) and as summarized below.

The testing apparatus consisted of four 10.75 -L stainless steel chambers that were treated with Sulfinert $^{\circledR}$ coating (Restec 2005; SilcoTech 2009; http://www.silcotek.com/), an inert silica layer that minimizes the interaction between the stainless steel and active compounds such as hydrogen sulfide, sulfur dioxide, and the low molecular weight mercaptans. The test materials were placed on a Sulfinert ${ }^{\circledR}$ coated screen resting in the horizontal orientation slightly below the center of the test chambers, and the chambers were sealed with clamp-on lids. The chambers were mounted inside an oven that provided a constant temperature and controlled atmosphere.

The standard, or baseline, test conditions for this work were as follows. The chamber temperature, $T\left({ }^{\circ} \mathrm{C}\right)$, was $25^{\circ} \mathrm{C}$; the inlet flow, $F$ (in liters per minute of carbon-filtered, preconditioned air) to each chamber was maintained at $1 \mathrm{~L}$ per minute and $50 \%$ relative humidity $(\mathrm{RH})$. The inlet flow was supplied continuously to each test chamber and the exhaust flow from each chamber was vented to a fume hood. The desired $R H$ was achieved by mixing streams of carbon/HEPA filtered air that was either dry or watersaturated as described for the conditioning chambers. The emitting surface area of the tested materials, including the front and back faces, $A\left(\mathrm{~m}^{2}\right)$, was approximately 0.04 (6inch-square pieces of drywall), resulting in a loading factor, $L\left(\mathrm{~m}^{2} / \mathrm{m}^{3}\right)$, of 3.7 and an

\footnotetext{
${ }^{1}$ Hexamethylcyclotrisiloxane (D3, CAS\#541-05-9); Octamethylcyclotetrasiloxane (D4, CAS\# 556-67-2); and Decamethylcyclopentasiloxane (D5, CAS\# 541-02-9).
} 
area-specific air flow rate $\left(\mathrm{m}^{3} / \mathrm{m}^{2} / \mathrm{h}\right)$ of 1.5 for each sample. The ventilation rate in the chambers was approximately 5.6 ACH. Although most emission factors were measured using these standard conditions, the initial method development phase of the study used a higher temperature and humidity and a reduced ACH. As a result, emission factors for some of the low molecular weight carbonyls, including formaldehyde, acetaldehyde, and acetone, were measured under the non-standard conditions, which are indicated along with the results.

The collection of air samples for measuring chemical emissions was initiated after the sample was loaded into the test chamber for a minimum of one hour in the test chambers to allow time for conditions to stabilize. Because the samples were pre-conditioned at the target $\mathrm{RH}$, the emission rates were expected to be constant such that the approach to steady state concentration in the chamber was expected to follow the exponential relationship described by Equation 1.

$$
\frac{C_{t}}{C_{s s}}=1-\exp (-k \times t)
$$

Where:

$C_{t}$ is the concentration (micrograms per cubic meter $\left[\mu \mathrm{g} / \mathrm{m}^{3}\right]$ ) in the chamber at elapsed time $t(\mathrm{~h})$ after loading the sample into the chamber;

$C_{s s}$ is the true steady state concentration $\left(\mu \mathrm{g} / \mathrm{m}^{3}\right)$ in the chamber; and

$k$ is the removal rate $\left(\mathrm{h}^{-1}\right)$ of the chemical from the chamber, where the lowerbound removal rate would be equivalent to the $\mathrm{ACH}$ for non-reacting chemicals.

Using Eq. 1 and assuming a constant emission rate with an $\mathrm{ACH}$ on the order of 5.6, the time to reach $99 \%$ of steady state (i.e., $C_{t} / C_{s s}=0.99$ ) is approximately one hour.

The air sampling methods and analytical methods are described in detail below, but in general, active samples were collected on commercially available thermodesorption tubes for VOCs and VSCs, and on derivatizing sorbent cartridges for aldehydes by pulling air directly from the chambers through the sampling tube. The sampling rate was maintained at less than $80 \%$ of the total flow through the chamber to prevent backflow of air into the test chamber. Solid-phase microextraction (SPME) commercially available fibers coated with a polydimethylsulfoxide/carboxnin layer (Sigma-Aldrich, 1998, Ras et al. 2008b) were used to passively sample sulfur gases directly from the chambers by inserting the SPME fiber through an access port the chamber. Each of these sampling and analysis methods is described below.

\section{Air Sampling and Analysis}

Four different combinations of sampling and analytical methods were utilized to characterize chemical emissions from the drywall materials: (1) a method utilizing thermodesorption gas chromatography mass spectroscopy (TD-GC/MS) to identify and quantify VOCs; (2) a derivitization-based sampling followed by liquid extraction and high-performance liquid chromatography with ultraviolet detector (HPLC-UV) to quantify low molecular weight carbonyls; (3) a thermodesorption gas chromatography sulfur chemiluminescence detector (TD-GC/SCD) to quantify VSCs; and (4) a solid- 
phase micro extraction gas chromatography sulfur chemiluminescence detector (SPME$\mathrm{GC} / \mathrm{SCD}$ ) to quantify reactive sulfur gases. Each method is described in detail below.

\section{Volatile Organic Compounds}

VOC samples were collected onto multibed sorbent tubes (P/N 012347-005-00; Gerstel or equivalent) having a primary bed of Tenax-TA sorbent backed with a section of Carbosieve. Tenax has been found to be a suitable sorbent material for actively sampling reactive sulfur compounds (Devai and Delaune, 1996; Pandey and Kim, 2009; Baltussen et al., 1999) but we were unable to retain the ultra volatile reactive sulfur gases in the GC inlet during thermodesorption. Therefore, the active sampling using Tenax/Carbosieve sorbent tubes was used only for the VSCs and the SPME method was developed (both approaches described later) for the RSGs.

Prior to use, the sorbent tubes were conditioned by a helium purge $(>10 \mathrm{cc} / \mathrm{min})$ at 280 ${ }^{\circ} \mathrm{C}$ for 60 minutes and sealed in Teflon-capped tubes. VOC samples were collected directly onto the sampling tubes from the exit port of the small emission chamber containing the test sample. A variable-speed peristaltic pump was used to pull air through the sample tubes at a rate of $\sim 200 \mathrm{cc} / \mathrm{min}$. Flows were checked at least twice during each sampling period using either a bubble flow meter or a DryCal gas flow meter (BIOS, 500 cc/min). Approximately $12 \mathrm{~L}$ were collected from the emission chamber. A backup sampling tube was used periodically to check for breakthrough. ${ }^{2}$ After samples were collected, the sorbent tubes were sealed with Teflon-lined caps and transferred to a freezer until analysis. Samples typically were analyzed within one day of collection. Sample stability for a wide range of VOCs has been confirmed previously in our lab after freezer storage times of more than 2 months.

Sorbent tubes were thermally desorbed for analysis by gas chromatography/mass spectrometry (TD-GC/MS) using a thermodesorption auto-sampler (Model TDSA2, Gerstel); a thermodesorption oven (Model TDS3, Gerstel); and a cooled injection system (Model CIS4, Gerstel). Desorption was performed in splitless mode, and the desorbed sample was refocused on the CIS4 inlet in solvent vent mode at flow of $30 \mathrm{cc} / \mathrm{min}$. Desorption temperature in the TDS3 oven started at $25{ }^{\circ} \mathrm{C}$ with a 0.5 -minute delay after loading the tube, followed by a $60{ }^{\circ} \mathrm{C}$ ramp to $250{ }^{\circ} \mathrm{C}$ and a 4 -minute hold time. The cooled injection system was fitted with a Tenax-packed glass liner (P/N 013247-005-00, Gerstel) that was held at $-10{ }^{\circ} \mathrm{C}$ throughout desorption and then heated within 0.2 minutes to $270{ }^{\circ} \mathrm{C}$ at a rate of $12{ }^{\circ} \mathrm{C} / \mathrm{second}(\mathrm{s})$, followed by a 3-minute hold time. Compounds were resolved on a GC (Series 6890Plus, Agilent Technologies) equipped with a 30meter HP-1701 14\% cyanopropyl phenyl methyl column (Model 19091U-233; Agilent Technologies) at an initial temperature of $1{ }^{\circ} \mathrm{C}$ for 0.5 minutes, then ramped first to $40{ }^{\circ} \mathrm{C}$ at $25{ }^{\circ} \mathrm{C} / \mathrm{min}$, then to $115{ }^{\circ} \mathrm{C}$ at $3{ }^{\circ} \mathrm{C} / \mathrm{min}$, and finally to $250{ }^{\circ} \mathrm{C}$ at $10{ }^{\circ} \mathrm{C} / \mathrm{min}$ holding for 10 minutes.

The resolved analytes were detected using an electron impact mass spectrometer (MS) (5973, Agilent Technologies). The MS was operated in scan mode. All compounds that exceeded the detection limit (1-5 nanogram [ng]) were identified by library search using

\footnotetext{
${ }^{2}$ Some earlier measurements were collected at $100 \mathrm{cc} /$ min during the method development phase of the project, but the higher flow rate of $200 \mathrm{cc} / \mathrm{min}$ provided better detection limits without resulting in breakthrough of either VOCs or VSCs. Therefore the final method utilized the higher sampling rate.
} 
the National Institute of Standards and Technology (NIST) mass spectral search program for the NIST/EPA/NIH mass spectral library (version 2.0d build April 26, 2005), followed by comparison to reference standards as needed. Multipoint calibrations were prepared from pure standards for quantification. When pure standards were not used, the analyte was reported in terms of toluene equivalence by comparing the instrument response for the total ion chromatogram (TIC) for the chemical to a multipoint calibration of TIC toluene. All pure standards and analytes were referenced to an internal standard ( $\sim 120 \mathrm{ng}$ ) of 1-bromo-4-fluorobenzene that was added directly to the thermodesorption tube before analysis.

\section{Low Molecular Weight Carbonyls}

The target analytes in the aldehyde analysis were formaldehyde, acetaldehyde, and acetone. Higher carbon-number aldehydes were analyzed using the VOC method described above. The volatile carbonyls including formaldehyde, acetaldehyde and acetone are quantified using USEPA Method TO-11 (McClenny and Holdren, 1999). As with the VOCs and VSCs (discussed below), air samples were drawn directly from the small emission chamber at steady state. Samples were collected on commercially available silica gel cartridges coated with 2,4-dinitrophenyl-hydrazine (XPoSure Aldehyde Sampler, Waters Corporation). A vacuum pump (Model DOA-P104-AA, Gast) was used to draw chamber air through the sample cartridge at $\sim 800 \mathrm{cc} / \mathrm{min}$; sample flow rates were regulated by electronic mass flow controllers. Sample cartridges were capped and stored in the freezer until extraction.

Prior to analysis, cartridges were eluted with 2 milliliters $(\mathrm{mL})$ of high-purity acetonitrile into 2-mL volumetric flasks, and the eluent was brought to a final volume of $2 \mathrm{~mL}$ before analysis. Extracts were analyzed by high-performance liquid chromatography (HPLC) (1200 Series, Agilent Technologies) using a $\mathrm{C}_{18}$ reverse-phase column with 65:35 $\mathrm{H}_{2} \mathrm{O}$ :acetonitrile mobile phase at $0.35 \mathrm{~mL} / \mathrm{min}$ and $\mathrm{UV}$ detection at 360 nanometers. Commercially available hydrazone derivatives of formaldehyde, acetaldehyde, and acetone were used to prepare multipoint calibrations for the target aldehydes.

\section{Volatile Sulfur Compounds}

Samples were collected for the volatile sulfur compounds (VSCs) using the same types of tubes and sampling method described above for the VOCs. Initially the VOCs and the VSCs were to be analyzed in parallel with a new GC equipped setup to run parallel MS and sulfur chemiluminescence detectors (SCD). Difficulties with the instrument, however, necessitated using the instrument and method described above for VOCs and the new instrument to focus on the VSCs as described here. Thus, two independent TDS samples were collected and analyzed separately for VSCs and VOCs. Results from the TDS samples for VSCs subsequently were used with the SPME samples, that were collected simultaneously with the VSCs and described in the next section, to determine the compound-specific sampling rate for the SPME fiber in the small chambers. This information facilitated the use of the SPME method for quantifying emissions across the full set of sulfur compounds (Sigma-Aldrich, 1998) in the emission chambers.

First the TD-GC/SCD method is described, followed by the method used to determine sampling rate for the SPME-GC/SCD method. SCD is suited to identifying and 
discriminate among extremely low concentrations of sulfur components (Yan, 2006); and SPME has been found to be effective in identifying VSCs in air (Ras et al., 2008b; Shirey, 1997). Both methods were used to quantify VSCs, as described in the results and discussion section. After the air samples were collected on the sorbent tubes $(\sim 12 \mathrm{~L})$, the samples were thermally desorbed for analysis by gas chromatography/sulfur chemiluminescence detection (TD-GC/SCD) and using a TD auto-sampler (Model TDSA2, Gerstel); a TD oven (Model TDS-G, Gerstel); and a cooled injection system (CIS) (Model CIS4, Gerstel). The cooled injection system was fitted with a glass bead packed inlet liner (P/N 013247-005-00, Gerstel). TDS desorption was performed in splitless mode with initial temperature $20{ }^{\circ} \mathrm{C}$, a 0.5 -minute delay, then a $120{ }^{\circ} \mathrm{C}$ ramp to $225^{\circ} \mathrm{C}$ and a 2.3 -minute hold time. The transfer line temperature was constant at $225^{\circ} \mathrm{C}$. The cryogenic inlet trap was held at $-120{ }^{\circ} \mathrm{C}$ throughout desorption phase and run in solvent vent mode with a vent flow of $30 \mathrm{cc} / \mathrm{min}$. Following TDS desorption, the CIS was heated to $150{ }^{\circ} \mathrm{C}$ at a rate of $16{ }^{\circ} \mathrm{C} / \mathrm{s}$, followed by a 0.71 -minute hold time. Compounds were resolved on a GC (Series 7890A, Agilent Technologies) equipped with a $30 \mathrm{~m} \times$ $0.32 \mathrm{~mm}$ DB1 column with 1-micron film thickness (Agilent J\&W DB-1). The initial temperature was $10{ }^{\circ} \mathrm{C}$ for $1 \mathrm{~min}$, then ramped at $8{ }^{\circ} \mathrm{C} / \mathrm{min}$ to $120{ }^{\circ} \mathrm{C}, 4{ }^{\circ} \mathrm{C} / \mathrm{min}$ to $180{ }^{\circ} \mathrm{C}$, then $16{ }^{\circ} \mathrm{C} / \mathrm{min}$ to $260{ }^{\circ} \mathrm{C}$ and held for $5 \mathrm{~min}$. The sulfur chemiluminescent detector was operated with $45 \mathrm{cc} / \mathrm{min}$ fuel, $52 \mathrm{cc} / \mathrm{min}$ oxidant, and a burner temperature of $800{ }^{\circ} \mathrm{C}$.

Initial identification of VSCs in the emission stream was accomplished using the GC described above but interfaced directly to a MS (5975C inert, Agilent Technologies). A 12-L sample was collected from a chamber containing three times the normal loading of a drywall sample (sample 7339) that previously had been identified as emitting the highest levels and widest range of sulfur-containing compounds (see results for VSCs). Following initial identification by mass spectral library search, the SCD detector was installed and a second 12-L sample was analyzed. The pattern of retention times and peak heights was used to identify the peaks in the SCD analysis based on results from the MS analysis. Then a series of pure standards was run to positively identify chemicals where pure standards were available and to determine the relationship between chemical structure and retention time. The pure standards were run individually by injecting 1 microliter $(\mu \mathrm{L})$ of pure standard into a warm dilution bulb $(2 \mathrm{~L})$ containing several glass beads, which then was allowed to rest in an oven at $70{ }^{\circ} \mathrm{C}$. An aliquot of the initial dilution subsequently was spiked into a second warm dilution bulb using a gas-tight syringe. Then a known aliquot of the diluted standard was transferred directly to a sampling tube and purged for several minutes before analysis. The results from the pure standards provide retention windows for a series of sulfides and disulfides of increasing symmetric alkyl number, as shown in Figure 1. Relative retention times are useful for qualitative identification of unknown contaminants (Castello, 1999; Goodner, 2008). The retention windows derived in this work from known standards were used to identify VSCs qualitatively in cases of an inconclusive match by either mass spectral or pure standard retention times.

The mass of each VSC was quantified by the sulfur chemiluminescence response. The SCD has a number of advantages for sulfur gas analysis over other detectors, including a wide linear range and equimolar response for all sulfur compounds, plus very good sensitivity and selectivity (Hua et.al., 2004; Yan, 2006; Pandey and Kim, 2009). The 
equimolar response allows for the quantification of all analytes in the sample, even unknowns, based on a single standard calibration. Several pure standards were used to develop a multipoint calibration for sulfur-containing chemicals. The initial work did not include an internal standard, but the final TD-GC/SCD method used thiophene (CAS\# 8014-23-1) generated in a diffusion oven and added to each sampling tube prior to analysis to track method performance.

After the chemical composition of the emission stream was characterized for the VSCs, two of the higher-emitting materials from the first set of drywall samples were tested using both TD-GC/SCD and SPME-GC/SCD simultaneously. This testing was done to estimate the apparent sampling rate for the SCD fiber in order to relate the SPME method described in the next section to the TD-GC/SCD calibration for sulfur across the range of compounds. The SPME method initially was developed specifically for the ultra-volatile reactive sulfur gases, but subsequent analysis indicated that the SPME fiber could be used for the full range of sulfur-containing compounds (Sigma-Aldrich, 1998) if the sampling rate for the chamber conditions was known. The relationship between the chemiluminescence detector response and the sample volume for either the SPME or TDS methods is given by:

$$
R_{i}=\frac{E F_{i} \times L_{s}}{A C H} \times V
$$

Where:

$R_{i}$ and $E F_{i}$ are the SCD response (area) and sample emission factor $\left(\mathrm{ng} / \mathrm{m}^{2} / \mathrm{h}\right)$, respectively, for chemical " $I$,";

$L_{s}$ is the loading of drywall sample " $s$ " in the chamber $\left(\mathrm{m}^{2} / \mathrm{m}^{3}\right)$;

$A C H$ is the air changes per hour in the chamber during sampling; and

$V$ is the sample volume $\left(\mathrm{m}^{3}\right)$.

The same equation applies to both the SPME sample and the TD sample, but because the SPME is a passive sampling method, we cannot directly measure the sampling rate or total sample volume. To estimate the apparent SPME sample volume we assume a constant chemical-specific emission rate $\left(E F_{i} \times L_{s}\right)$ for both the TDS and SPME samples, then expand Eq. 1 to include both sampling methods and solve for the apparent SPME sample volume:

$$
V_{S P M E}=\frac{R_{S P M E-i} \times A C H_{S P M E}}{R_{T D S-i} \times A C H_{T D}} \times V_{T D}
$$

Five measurements were collected using both the SPME and TDS sampling methods for two different drywall samples, resulting in 70 chemical-specific SPME/TDS response ratios. The resulting sampling rate, or volume, indicated a slight decreasing trend with increasing retention time. Because the sample size was insufficient to model this trend, an average sample volume is used across all chemicals eluting after the last reactive sulfur gas (carbon disulfide). Details are provided in the results section, but the apparent sampling rate for the VSCs sampled on the SPME fiber, given the standard chamber 
conditions, is $\sim 31 \mathrm{~mL} / \mathrm{min}$ (coefficient of variation, 30\%), resulting in an apparent sample volume throughout the 50-minute SPME sample period of $1.6 \mathrm{~L}$. This sample volume is used, along with the chemical-specific mass (sulfur equivalent) determined from the SPME-GC/SCD analysis and equations described in the data analysis section, to estimate VSC emission factors for some of the drywall samples.

\section{Reactive Sulfur Gases}

LBNL explored various active sampling methods for quantifying the reactive sulfur gases, including (1) on-line cryogenic sampling whereby chamber air is drawn directly into a cryogenically cooled thermodesorption tube and desorbed into the cooled injection system (see Pandey and Kim, 2009 for discussion of cryogenic trapping), (2) on-line cryogenic sampling through a Nafion drying tube (http:/www.permapure.com/) to reduce icing in the cryogenic trap and inlet, and (3) direct large-volume (1 to $5 \mathrm{cc})$ injection from chamber to cooled injection system. Various sorbent materials and temperature regimes also were tested. None of the conditions provided satisfactory results for the reactive ultra volatile sulfur gases due to interferences, low response and/or inconsistent recoveries. Therefore, we elected to use a SPME sampling approach as recommended by SigmaAldrich (1998) and used in Ras et al. (2008b) but modified to sample directly from the emission chamber.

A carboxen/polydimethylsiloxane (CAR/PDMS, Supelco) stationary phase $(0.75 \mu \mathrm{m}$ film thickness) installed in a manual SPME holder was conditioned in the $\mathrm{GC}$ inlet at $300{ }^{\circ} \mathrm{C}$ with elevated purge flow for two hours before use. CAR/PDMS fibers have been found to be the most inert material for collecting volatile and reactive sulfur compounds (Baltussen et al., 1999). PDMS with Carboxen has been found to achieve the best sensitivity for most reduced sulfur compounds (Pandey and Kim, 2009). The holder was inserted through a sampling port mounted in the front of the emission chamber, and the fiber was extended into the chamber to start the sampling. A 50-minute sampling period was found to provide adequate response for the range of reactive sulfur gases, as shown in Figure 2. Ras et al. (2008) found that analytes reached equilibrium conditions at 45 min with SPME. After sampling, the SPME fiber was retracted then immediately transferred to the hot $\left(250{ }^{\circ} \mathrm{C}\right)$ injector and the fiber was extended into the injector in splitless mode for $2 \mathrm{~min}$ followed by a $50-\mathrm{mL} / \mathrm{min}$ purge for $1 \mathrm{~min}$ and then a $15-\mathrm{mL} / \mathrm{min}$ purge for the rest of the run. The fiber remained in the inlet for at least $10 \mathrm{~min}$ before retracting the fiber and returning the sampler to the emission chamber to start collecting the next sample. The column flow in the GC during analysis was $1 \mathrm{~mL} / \mathrm{min}$ and oven start temperature was $-50{ }^{\circ} \mathrm{C}$ held for $2 \mathrm{~min}$, then increased first to $100{ }^{\circ} \mathrm{C}$ at $10{ }^{\circ} \mathrm{C} / \mathrm{min}$, then to $180{ }^{\circ} \mathrm{C}$ at $4{ }^{\circ} \mathrm{C} / \mathrm{min}$, and finally to $260{ }^{\circ} \mathrm{C}$ at $16{ }^{\circ} \mathrm{C} / \mathrm{min}$ and held for $5 \mathrm{~min}$. The column and detector were as described for the VSC analysis. The SPME fiber was stored in the hot injector between sampling periods.

\section{Data Analysis}

LBNL calculated the material-specific emission rates from measurements collected from the small chambers at steady state. Under steady state conditions, the concentration in the chamber is constant so that a simple mass balance can be used to estimate emission rates as a function of measured concentration. The steady state form of the mass balance 
equation for calculating area-specific emission factors, $E F\left(\mu \mathrm{g} / \mathrm{m}^{2} / \mathrm{h}\right)$, in a well-mixed system is:

$$
E F=\frac{F \times\left(C-C_{B}\right)}{A}
$$

Where:

$F\left(\mathrm{~m}^{3} / \mathrm{h}\right)$ is the ventilation flow rate,

$A\left(\mathrm{~m}^{2}\right)$ is the exposed surface area of the test material,

$C\left(\mu \mathrm{g} / \mathrm{m}^{3}\right)$ is the measured steady state concentration in the chamber, and

$C_{B}\left(\mu \mathrm{g} / \mathrm{m}^{3}\right)$ is the background or blank concentration in the empty chamber.

The air change rate in the chamber, $A C H(\mathrm{~L} / \mathrm{h})$, is the ventilation rate divided by the chamber volume $(F / V)$. The loading factor of the material, $L\left(\mathrm{~m}^{2} / \mathrm{m}^{3}\right)$, is the exposed surface area of the test material divided by the chamber volume. Thus, an alternate solution to Equation 3 is:

$$
E F=\frac{A C H \times\left(C-C_{B}\right)}{L}
$$

Which is the form used to estimate emission factors in this work.

\section{RESULTS AND DISCUSSION}

This section describes and discusses the measured emissions from the drywall samples, including emissions of volatile organic compounds (VOCs), low molecular weight carbonyl, volatile sulfur compounds (VSCs), and reactive sulfur gases (RSGs).

\section{Overview of Experimental Results}

The small-chamber emissions testing facility at LBNL was used to determine standard emission factors for 30 samples of drywall provided by the CPSC. Unless otherwise indicated, all emission factors were determined at $25{ }^{\circ} \mathrm{C}$, at $50 \%$ relative humidity, and with an air flow rate of $\sim 1.5 \mathrm{~m}^{3}$ air per $\mathrm{m}^{2}$ emitting surface area per hour. Emission factors are reported in units of $\mu \mathrm{g} / \mathrm{m}^{2} / \mathrm{h}$ for volatile organic compounds (VOCs), low molecular weight aldehydes, and reactive sulfur gases (RSGs), and in units of $\mathrm{ng} / \mathrm{m}^{2} / \mathrm{h}$ for volatile sulfur compounds (VSCs). The results are summarized by analytical method and presented graphically; complete results are listed in tables at the end of the report. The second set of 13 drywall samples were tested blind; i.e., the analyst did not know the source, history, or status of the samples being tested, so for consistency, all results in this section are presented without interpretation or comparison.

\section{Emissions of Volatile Organic Compounds}

Figure 3 compares the total ion chromatograms for VOCs in the emission stream from the first 17 drywall samples tested. Because all the measurements were collected using the same air sample volume and chamber conditions, the peak height on the chromatograms 
indicate the relative emissions from each sample. The chromatograms are sorted based on the height of the tallest peak. The first significant peak in all the samples is the internal standard (4-bromofluorobenzene, BFB, CAS \# 460-00-4). The only other significant peak in the spectra is butylated hydroxytoluene (BHT, CAS \# 128-37-0). We not that subsequent work on a different project that the new low VOC tape that we started using during this project may have been a source of BHT but this has not been confirmed. Therefore, we report the results for BHT with the caveat that it may be an experimental artifact. The four digits to the right of each chromatogram in Figure 3 correspond to the last four digits of the CPSC drywall sample tracking number. The chromatogram for sample 8036 is only partly visible at the bottom of the figure because of an instrument failure during the analysis. Sample 8036 was re-tested along with the second set of 13 samples. All material emission factors are listed in Table 1.

The presence of lower-concentration VOC emissions is illustrated in Figure 4, which zooms in on the response axis of the total ion chromatogram for sample 7339. Most of the chemicals in the emission stream are near or below the limit of quantitation (LOQ) of about 1 nanogram (ng), representing a lower-bound measurement of emission factors of $\sim 0.2 \mu \mathrm{g} / \mathrm{m}^{2} / \mathrm{h}$. Values above the LOQ are listed in bold text in Table 1. Emission factors that were below the LOQ are also listed as values in standard for all chemicals detected in the emission stream but these values should be considered qualitative.

The VOC emission factors from all 30 drywall samples are summarized graphically in the stacked column chart in Figure 5. Refer to Table 1 for emission factors. The purpose of the stacked column format in Figure 5 is to show the total VOC emissions at a glance and the relative contribution of several chemicals to the emission stream. Considering all samples, the primary VOC constituents in the emission streams were butylated hydroxytoluene ${ }^{3}$, hexanal, and 1-chlorododecane followed by numerous chemicals having lower emission factors. Only the first 11 chemicals are identified in Figure 5. The remaining 15 identified VOCs in the emission stream are combined and reported as "other."

Table 1 summarizes the VOC emission factors for all chemicals and all samples tested. All values are corrected for background levels in the chambers and analysis (i.e., they are blank-corrected values). Results are reported for all values that exceed the limit of detection (LOD). Although values for emission factors that exceed the LOD but are less than the LOQ indicate the presence of the chemical in the emissions stream, the reported values should be considered an approximation only. Values that exceed the LOQ are listed in bold type. The first three rows of the table also include results for the low molecular weight aldehydes that were measured using the HPLC-UV method and that are described in the next section.

\footnotetext{
${ }^{3}$ Butylated hydroxytoluene was subsequently found to be an artifact of the aluminum tape used to seal the edges on building materials being tested in the emission chambers. Method blanks performed during this study, including the tape, did not show elevated levels of VOCs but a subsequent project did indicate that the tape may be a source of BHT. Therefore, the reader is cautioned that the results reported for BHT emissions from drywall are not yet confirmed.
} 


\section{Emissions of Low Molecular Weight Carbonyls}

Because the low molecular weight carbonyls, including formaldehyde, acetaldehyde, and acetone, are reactive and highly volatile, they are not readily quantified using the VOC method. Emission factors for those three chemicals were measured separately using the HPLC-UV method. The results are summarized graphically in Figure 6 and tabulated along with the VOC results in Table 1 (first three rows).

Initially the project intended to measure all emission factors at elevated temperature $(T)$ and humidity $(R H)$. Instrumentation problems stemming from the elevated moisture in the samples required measuring emission factors for the VOCs, and sulfur containing compounds at a lower (standard) $T$ and $R H$. The HPLC-UV method, which sampled using a derivatization step that was not affected by the elevated $T$ and $R H$ so the first set of 17 drywall samples are reported for those elevated conditions. The second set of 13 drywall samples are reported for standard conditions. The emission factors in Figure 6 are sorted from high to low based on the sum of formaldehyde, acetaldehyde, and acetone emission factors (background-corrected). The values from the measurements under higher $T$ and $R H$ are presented to the left of the vertical line on the chart, and the values from measurements under standard $T$ and $R H$ are presented to the right of the line in Figure 6. It has been established that elevated $T$ and $R H$ increases emission rates of formaldehyde from a variety of building materials (Van Netten et.al, 1989; Zhang et.al., 2007; Parthasarathy et.al., 2010).

\section{Emissions of Volatile Sulfur Compounds}

Figure 7 compares the sulfur gas emission fingerprints for the first 17 drywall samples tested. The chromatograms shown in Figure 7 are from the solid phase micro extraction (SPME) sampling approach using the sulfur chemiluminescence detector (SCD) so it shows the full range of sulfur gases emitted including both the VSCs and the RSGs. Although the SCD provides equimolar response to sulfur, possible differences in the passive sampling rate (Ras et.al., 2008) on the SPME fiber mean that the peak areas are not necessarily proportional to emissions of individual chemicals, as discussed later in this section. Figure 7 is separated into two regions, as indicated by the labeled brackets above the chromatograms. The first region comprises the RSGs quantified using the SPME method (see next section). The second region comprises the VSCs. The preferred method for quantifying VSCs was by active sampling on Carboseive-backed Tenax tubes that are thermally desorbed for analysis using the TD-GC/SCD method. However, to extend the SPME method to the full set of sulfur gases for use in future work with the small chambers, the sampling rate for the SPME fiber was estimated using results from parallel samples collected using both sampling methods. This extended SPME method then was used to quantify VSC emission factors for several of the samples, as described later in this section.

The chromatograms in Figure 7 are sorted from top to bottom in descending order based on the total sulfur gas response area from each sample. The large peak in the first three samples that elutes around 27 minutes was consistently lower based on the TD-GC/SCD method, indicating that this peak may be an artifact in the SPME sampling due to unusually rapid sampling rate on the SPME fiber, or strong preferential partitioning into the fiber from the air. The figure is intended to provide an overall comparison of the fingerprints of the emissions streams from the samples. 
A chromatogram for sample 7339, measured using the TD-GC/SCD method, is shown in Figure 8. This is the same sample as shown in the top-most chromatogram in Figure 7. Given the equimolar response of the SCD and the comparable sample volume collected using the active air sampling approach, the peak heights in Figure 8 are proportional to sulfur. Each peak represents a unique chemical and the relative peak heights indicate the relative emission strength of each chemical in the emission stream normalized to sulfur content. Sample 7339 was found to have the most consistent chemical fingerprint for the widest range of VSCs of all the samples tested. This sample therefore was used to identify the sulfur gases during method development, as described earlier in the methods section. A total of 39 VSCs were identified in the emission stream, and an additional three chemicals tentatively were identified as C-8 disulfides (chemicals having a disulfide bond and containing 8 carbon atoms) based on retention time windows derived in this work and shown in Figure 1 (see Castello, 1999 for a discussion of retention index systems and relative retention times used to identify compounds) and major ions in the mass spectrum.

The sulfur chemiluminescence detector is much more sensitive to sulfur-containing chemicals than is the mass spectrometer used in the VOC analysis. The VSC measurement shown in Figure 8 was collected simultaneously with a VOC measurement. Results for the low level VOC measurements were presented in Figure 4. The sulfurcontaining chemicals in Figure 8 were well below the approximate LOQ shown in Figure 4 using the mass spectrometer. For perspective, the largest peaks shown in Figure 8 are at or below the grey line that indicate the LOQ in Figure 4.

The VSC emission factors for all samples are summarized graphically in the stacked column chart in Figure 9. The approach used to estimate the sampling rate or sample volume for the SPME fiber was described earlier in the methods section. The resulting estimated SPME sample volumes are plotted relative to retention times in Figure 10. Although there is a slight decreasing trend with increasing retention time, the scatter in the data did not allow this trend to be modeled. Therefore an average sample volume (1.55 L for 50-minute sampling time) was used for all chemicals to estimate concentrations and subsequent emission factors.

The advantage of using the extended SPME approach is that the method provides both RSG and VSC results from a single measurement, and the highly controlled conditions in the small emission chambers provide good precision with the SPME fiber. The average coefficient of variation was $15 \%$ for the top 12 chemicals measured in replicate SPME samples, with precision ranging from $4 \%$ to a high of $37 \%$.

All of the chemical-specific emission factors for VSCs are reported in Table 2 for the tested drywall samples. For the VSCs, the lowest calibration point was $\sim 3$ picogram (pg); the lowest reported value of the known analytes in the samples was $\sim 1 \mathrm{pg}$; and the integration method for the SCD was set up to reject peaks having an area less than about $0.65 \mathrm{pg}$ where all mass values are reported as sulfur equivalent ${ }^{4}$. Using the average

\footnotetext{
${ }^{4}$ Because the SCD output is reported as mass of sulfur, the results reported here are normalized to sulfur equivalent mass in each compound. To convert from the sulfur equivalent mass to the molecular mass of chemical " $\mathrm{i}$ ", multiply the reported emission factor $\left(\mathrm{ng}-\mathrm{S} / \mathrm{m}^{2} / \mathrm{h}\right)$ by the $M W_{i} / 32 / n_{s}$ where $M W_{i}$ is the molecular weight of the compound, 32 is the mass of a sulfur atom and $n_{s}$ is the number of sulfur atoms in the molecule.
} 
sample volume, loading factor, and air change rate from the study, the values correspond to a lower-bound emission rate for the method of about $0.1 \mathrm{ng}-\mathrm{S} / \mathrm{m}^{2} / \mathrm{h}$. Therefore, all values reported in Table 2 exceed the LOQ.

\section{Emissions of Reactive Sulfur Gases}

Fingerprints for emissions of reactive sulfur gases (RSGs) are compared on the left side of Figure 7, along with the other VSCs for the first 17 samples. The chromatography of the ultra-volatile and reactive sulfur gases tailed significantly, as shown for sample 7339 in Figure 11. To resolve the first three chemicals, a tangent skim integration method was used first to integrate the carbonyl sulfide and sulfur dioxide. Then the combined area was integrated, and hydrogen sulfide was calculated as the difference.

After further testing, we found that the chromatographic tailing could be reduced significantly by ventilating the chamber with nitrogen instead of air. We also discovered during this testing that diluting the calibration standard for the RSGs with air resulted in the formation of $\mathrm{SO}_{2}$. This elevated $\mathrm{SO}_{2}$ did not occur when the calibration gas was diluted with nitrogen, indicating that oxidation was occurring either in the chamber or on the SPME sampling fiber or in the instrument inlet even within the short period required to measure the emissions. Kovalenko et al. (2001) discuss the formation of excessive amounts of polysulfides during oxidation of hydrogen sulfide with oxygen. Work by Bandosz, 2002, found that hydrogen sulfide could be oxidized on activated carbon although the Carboxen sorbent used in the SPME sampling is a different form of carbon. Other workers, such as Ras et al. (2008a), have optimized their analytical protocol for TD-GC/MS by using $99.999 \%$ pure helium during thermal desorption and helium gas as a carrier to GC and an inert MS to reduce potential oxidation artifacts. Others found that using Carboxen as an adsorbent (as applied to the PDMS stationary film on the SPME fiber) can produce large quantities of sulfur compounds as artifacts during desorption (Devai and Delaune, 1996). Therefore, we note that the SO2 measured in the emission stream from drywall samples in this study may be in part due to the oxidation of hydrogen sulfide. We report the results as measured with the $\mathrm{H}_{2} \mathrm{~S}$ and $\mathrm{SO}_{2}$ reported separately but there is a strong possibility that the sulfur in the $\mathrm{SO}_{2}$ is an artifact of oxidation of $\mathrm{H}_{2} \mathrm{~S}$. Confirming the source of $\mathrm{SO}_{2}$ requires further investigation.

The measured emission factors for the RSGs are summarized graphically in the stacked column chart in Figure 12. The actual values for the emission factors are given in Table 3. Table 3 is oriented differently than the previous tables, in which the CPSC tracking numbers are listed as row headings and the chemical names are given as column headings.

The RSGs reported in Table 3 were sampled passively usign the SPME fiber. The lowest calibration point for the method was about 0.8 parts per billion (ppb), or $\sim 1 \mu \mathrm{g}-\mathrm{S} / \mathrm{m}^{3}, \mathrm{a}$ value limited more by our ability to dilute the calibration standard gas than by the instrument detection. In addition, the detection and quantification limits differ for the chemicals depending on the passive sampling rate and how each chemical partitions into the PDMS/Carboxen film. The integration method was set up to reject peak areas less than a value that represented approximate emission factors for hydrogen sulfide, carbonyl sulfide, sulfur dioxide, methyl mercaptan, ethyl mercaptan, and dimethyl sulfide of 0.54 , $0.47,0.21,0.06,0.01$, and $0.01 \mu \mathrm{g}-\mathrm{S} / \mathrm{m}^{2} / \mathrm{h}$, respectively. 


\section{CONCLUSION}

Emission factors are reported for 75 chemicals, determined using four different sampling and analysis methods, and representing 30 different drywall samples encompassing both domestic and imported stock and a range of manufacturing types. The values reported here can be used to calculate preliminary exposure concentrations in residences by relating the emission factors to drywall loading in the residence. We note, however, that the measurements presented in this Interim Report were collected under a single set of environmental conditions, so there is uncertainty in relating emission factors derived from the small chamber measurements to whole-house exposure concentrations.

Further steps designed to reduce the uncertainty in predicted exposure concentrations might include experiments designed specifically to determine (1) the deposition velocity of emitted chemicals, including reactive sulfur gases, to common indoor surfaces; (2) the relationship between emission rates from drywall and ventilation rates more typical of residences; (3) the influence of temperature and relative humidity on emission factors; and (4) the effect of drywall coverings - including plasters, paints, and papers - that have differing porosities.

There may be opportunities for further interpretation of the emission factor data when the drywall materials are categorized (i.e., domestic, imported, natural, synthetic, mixed, year of production). We anticipate that further data analyses can be performed to compare emissions of the chemical constituents and identify statistically different categories of material. After the data are categorized (based on either statistical analysis or empirical information such as domestic versus imported or synthetic versus natural), then standard procedures can be used to construct statistical distributions for emission factors. Such statistical distributions could facilitate analysis designed to reduce uncertainty by using probabilistic modeling to combine the laboratory-based emissions measurements with results from field studies that measure whole-house concentrations. 


\section{FIGURES}

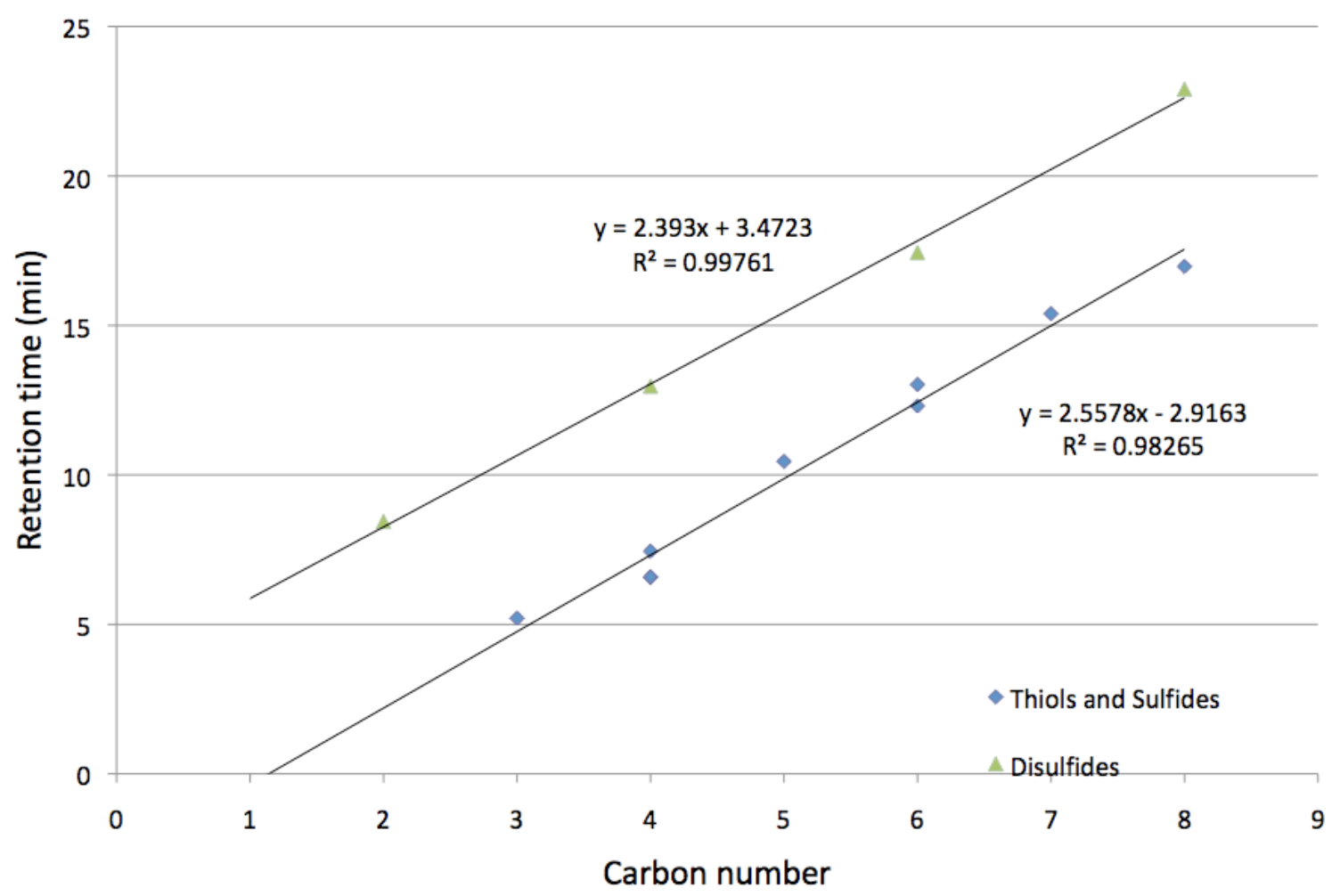

Figure 1: Relationships between chromatographic retention times using the method for volatile sulfur chemicals and the number of carbon atoms in sulfides (solid diamonds) or symmetric disulfides (solid triangles). 


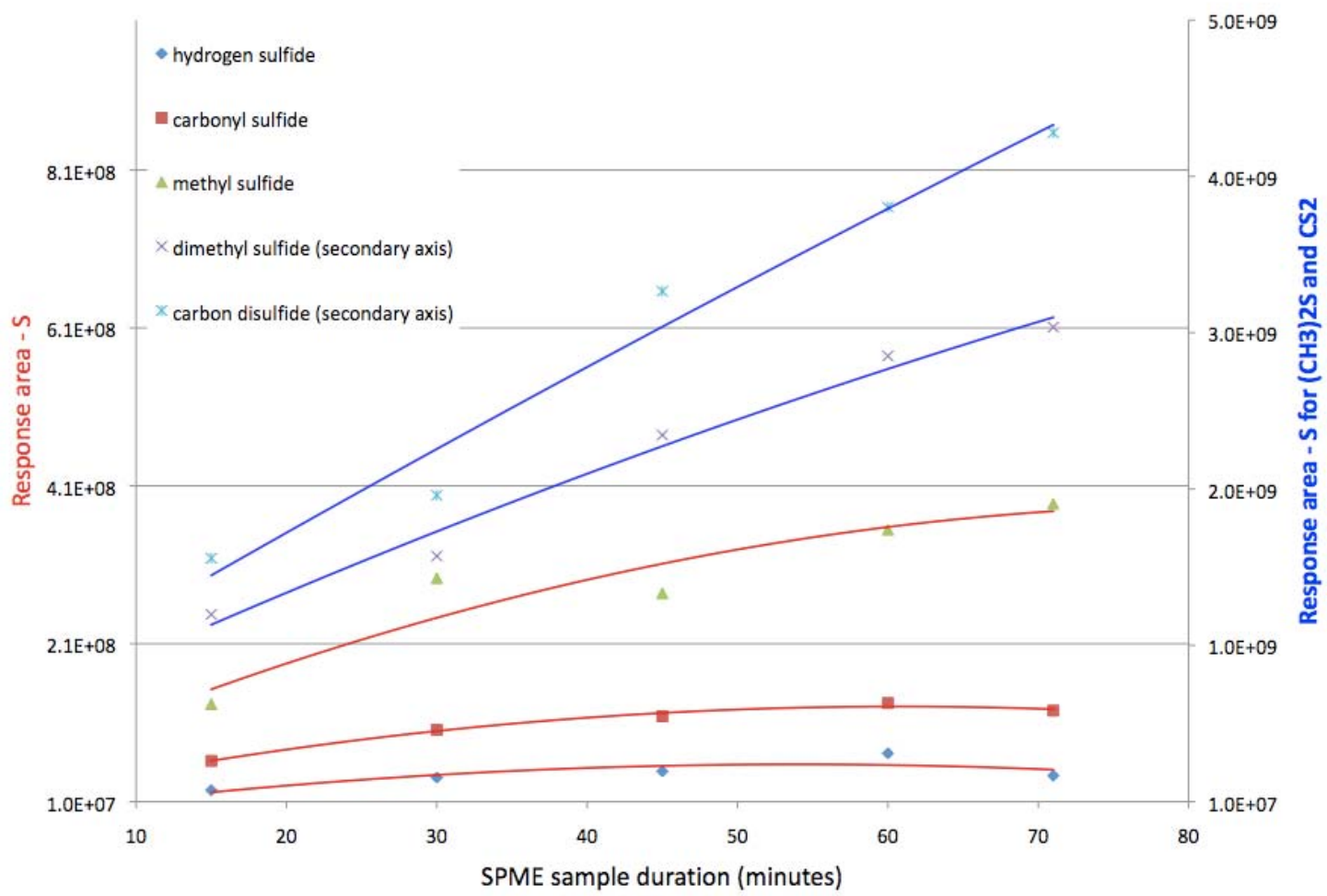

Figure 2: During development of the solid-phase microextraction (SPME) method the sampling rate was evaluated to determine the optimum sampling time. Fifty minutes was selected as an appropriate sample time to provide adequate response for a range of chemicals within the time constraints of the analysis by gas chromatography. This figure also illustrates the difference in partitioning into the SPME fiber for the sulfur gases and shows that as the molecular size increases, the uptake rate becomes linear over the full 50minute sampling period. 


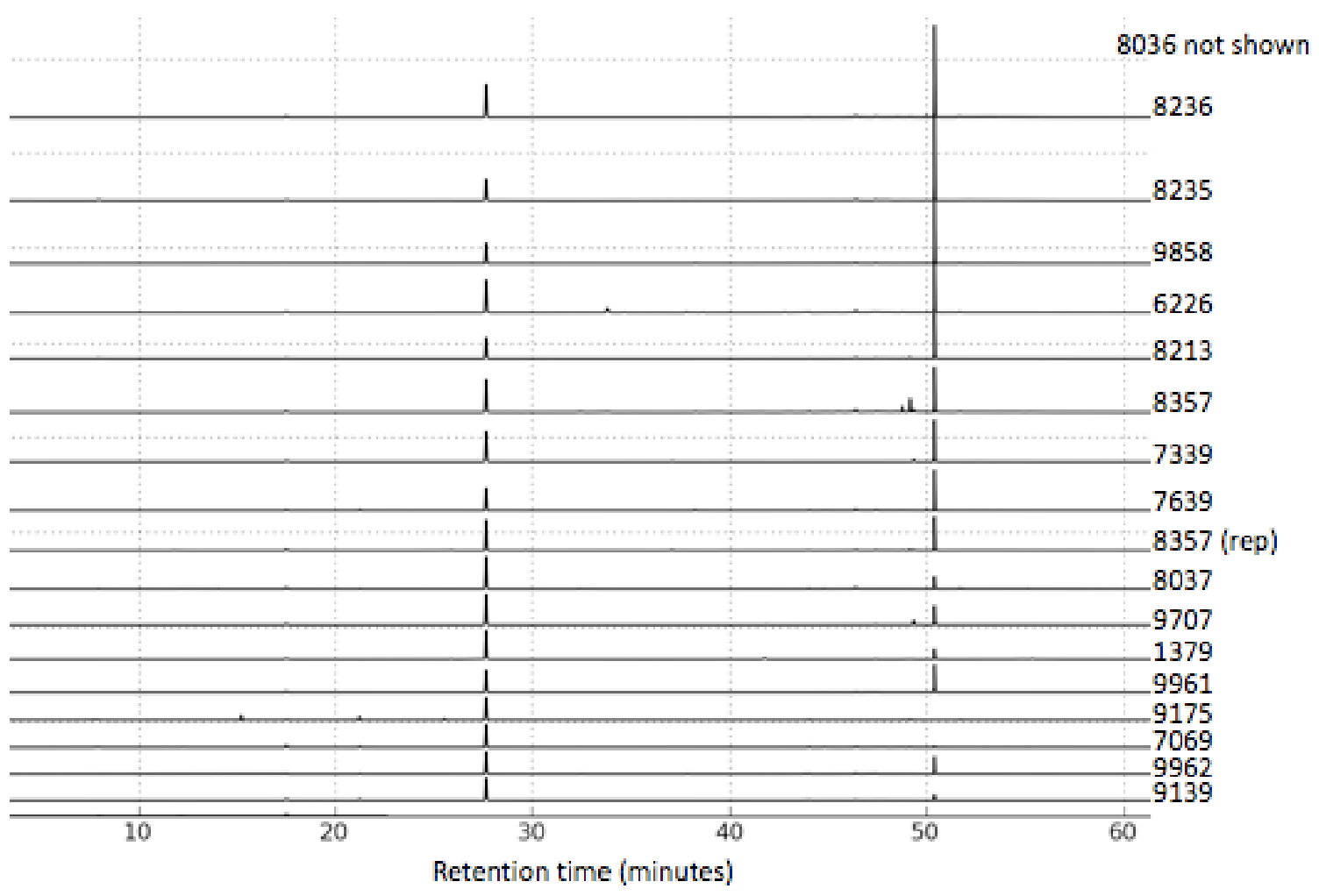

Figure 3: Total ion chromatograms for volatile organic chemicals are compared for the first 17 samples tested. The peak at about 28 minutes is the internal standard added to each sample before analysis. The larger peak after 50 minutes represents butylated hydroxytoluene. Other chemicals were identified at very low concentrations, as shown in the chromatogram in Figure 4 and as reported in Table 1. 


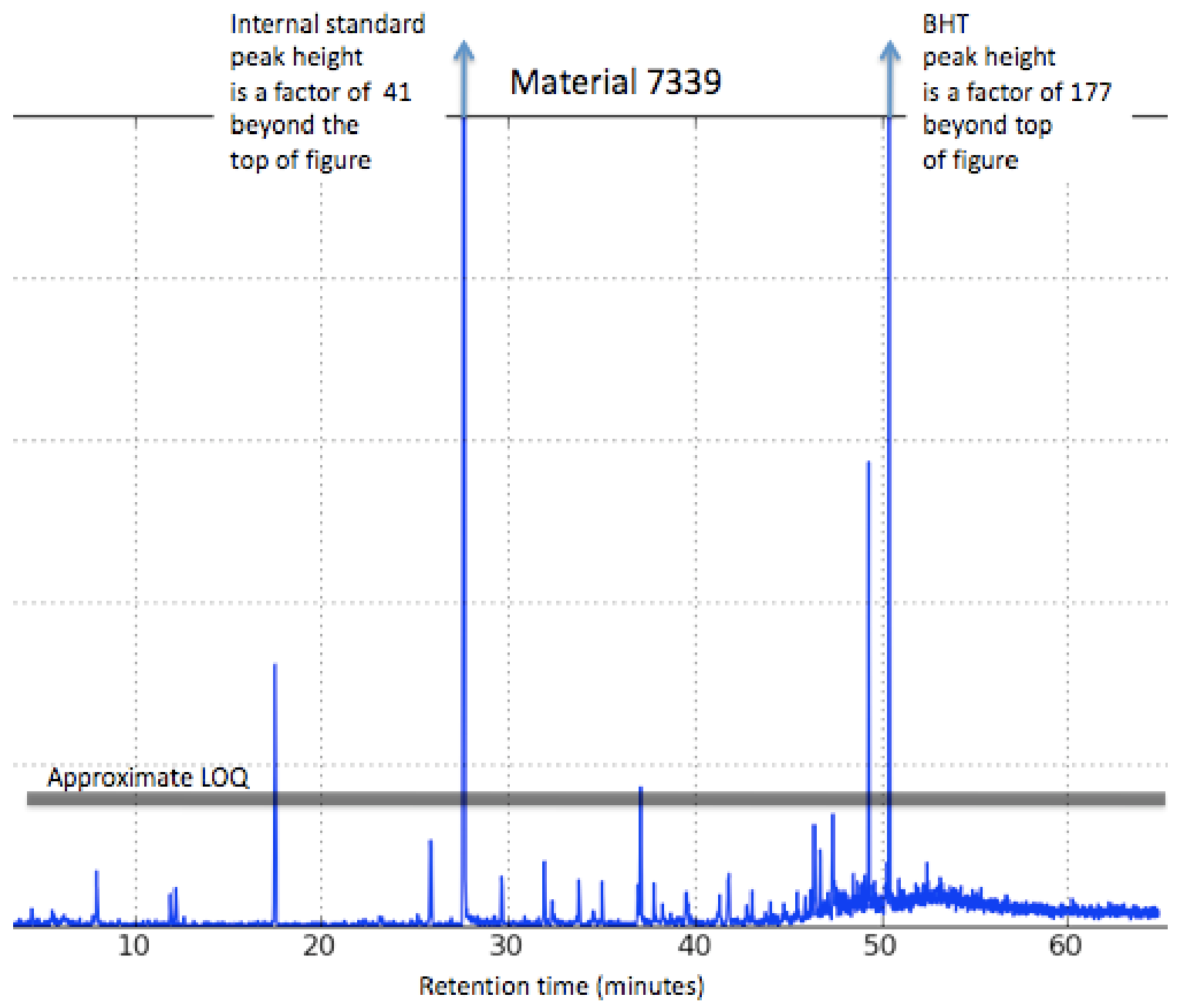

Figure 4: This figure zooms in on the chromatogram from Figure 3 at the peak height (y-axis) to show the chromatographic fingerprint of the lower-concentration volatile organic chemicals in the emission stream for sample 7339. Only a few of peaks (chemicals) exceed the approximate limit of quantitation of about 1 $n g$, representing an emission factor of $\sim 0.2 \mu \mathrm{g} / \mathrm{m}^{2} / \mathrm{h}$. 


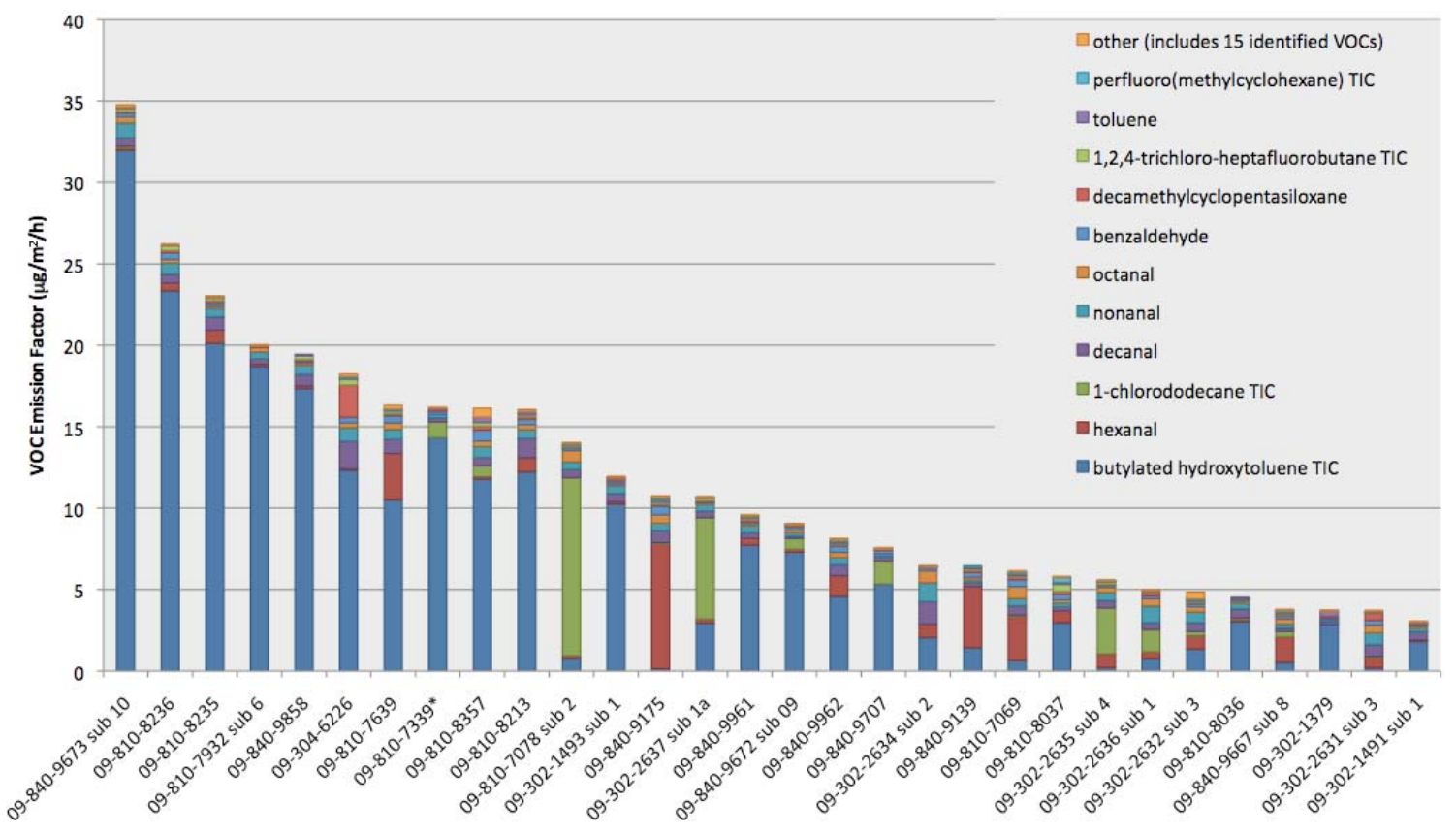

Figure 5: A compilation of total emissions of volatile organic chemicals from the tested samples. The CPSC material tracking number is listed across the category axis. The legend lists the specific chemicals in the order in which they are stacked. The chemicals having "TIC" at the end of their names were quantified as toluene based on their total ion chromatogram. 


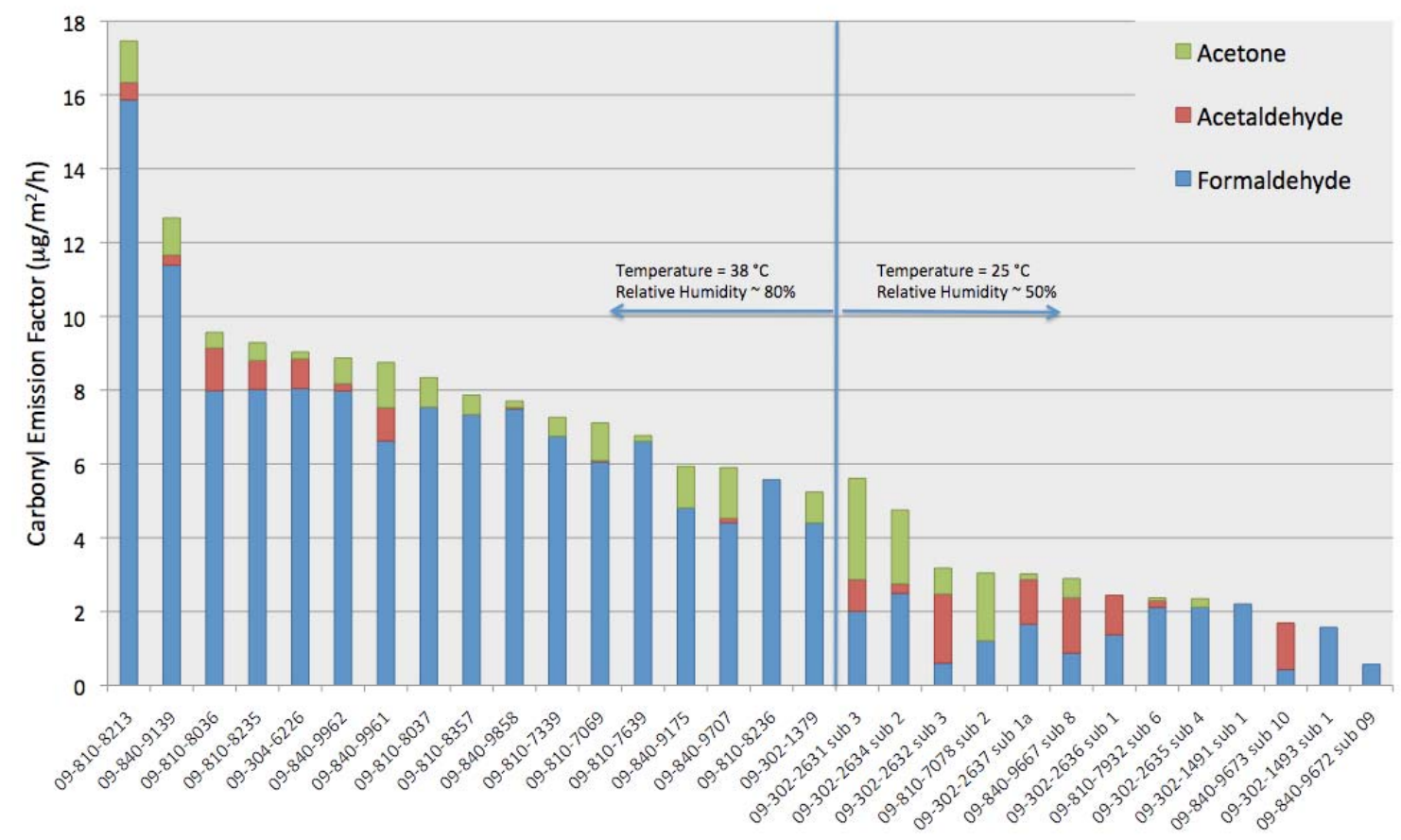

Figure 6: The sum of low molecular weight carbonyl emissions from the tested samples. The CPSC material tracking numbers are listed across the category axis. The legend lists the specific chemicals in the order in which they are stacked. Samples reported to the left of the vertical line were measured at a temperature of $38 \mathrm{C}^{\circ}( \pm 1 \%$ coefficient of variation) and relative humidity $(R H)$ of $69 \%( \pm 7 \%)$. The values to the right of the vertical line were measured at $25 \mathrm{C}^{\circ}( \pm 1 \%)$ and $49 \% \mathrm{RH}( \pm 3 \%)$. 


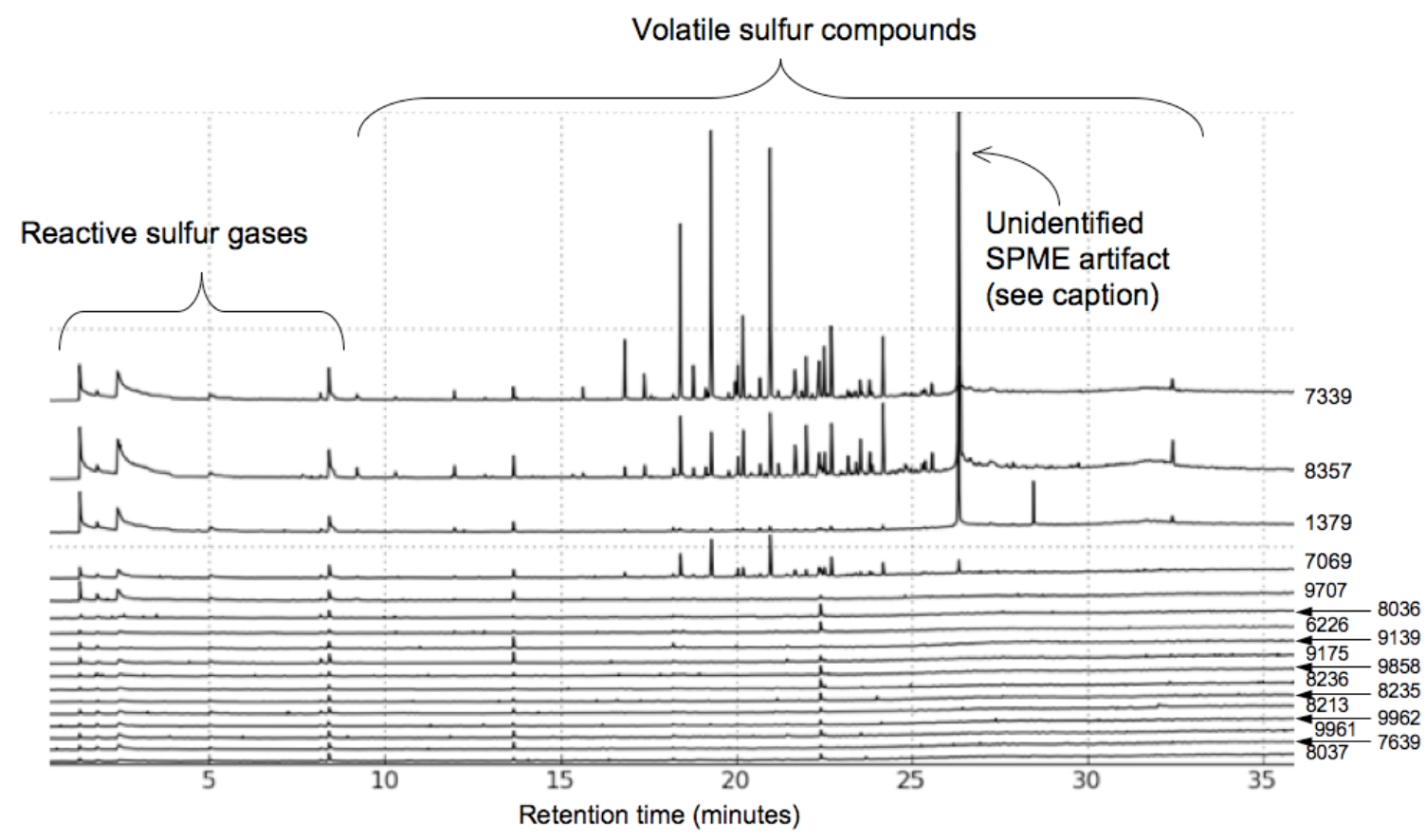

Figure 7: Comparison of sulfur gas emission fingerprints for the first 17 samples tested. The chromatograms are derived from 50-minute solid-phase microextraction (SPME) samples quantified using the sulfur chemiluminescence (SCD). Thus although all sulfur gases emitted from the drywall samples (RSGs and VSCs) are shown, the response area of the peaks are not proportional to the relative strength of the individual chemical emissions. The RSGs are represented by the peaks eluting in the first 8 minutes, and the VSCs are represented by the remaining peaks. The last four digits of the CPSC tracking number are listed down the right side of the figure. The chromatograms are sorted from top to bottom based on descending total sulfur gas emissions. The possible unidentified SPME artifact is discussed in the body of the report. 


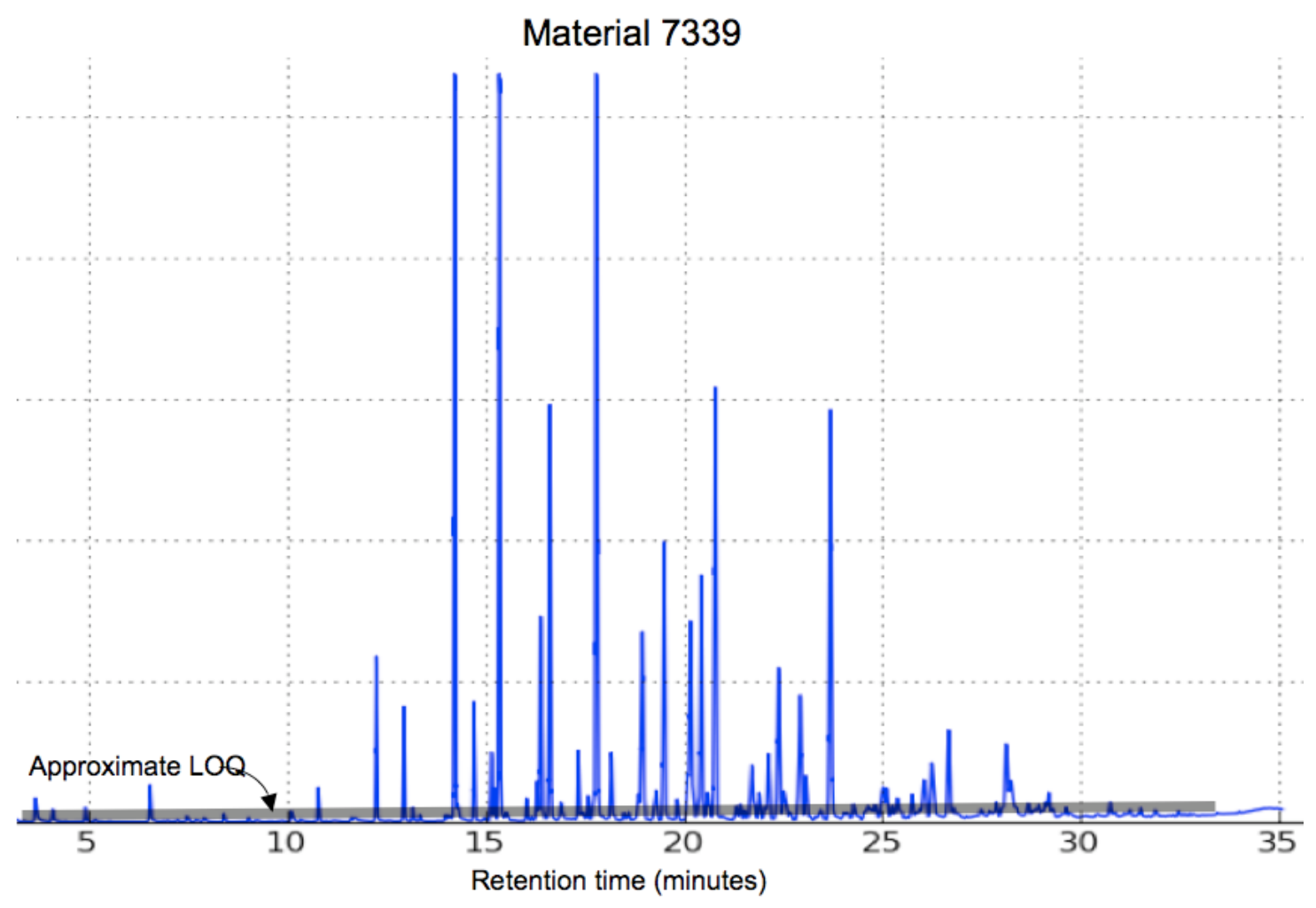

Figure 8: A single chromatogram from one of the samples listed in the previous figure but using the sampling method for volatile sulfur chemicals, not the SPME method. The grey line shows the approximate limit of quantification for this method. In this figure, given the equimolar response of the detector, the peak areas (and heights) are approximately proportional to the sulfur gas emission rate in terms of the mass of sulfur. 


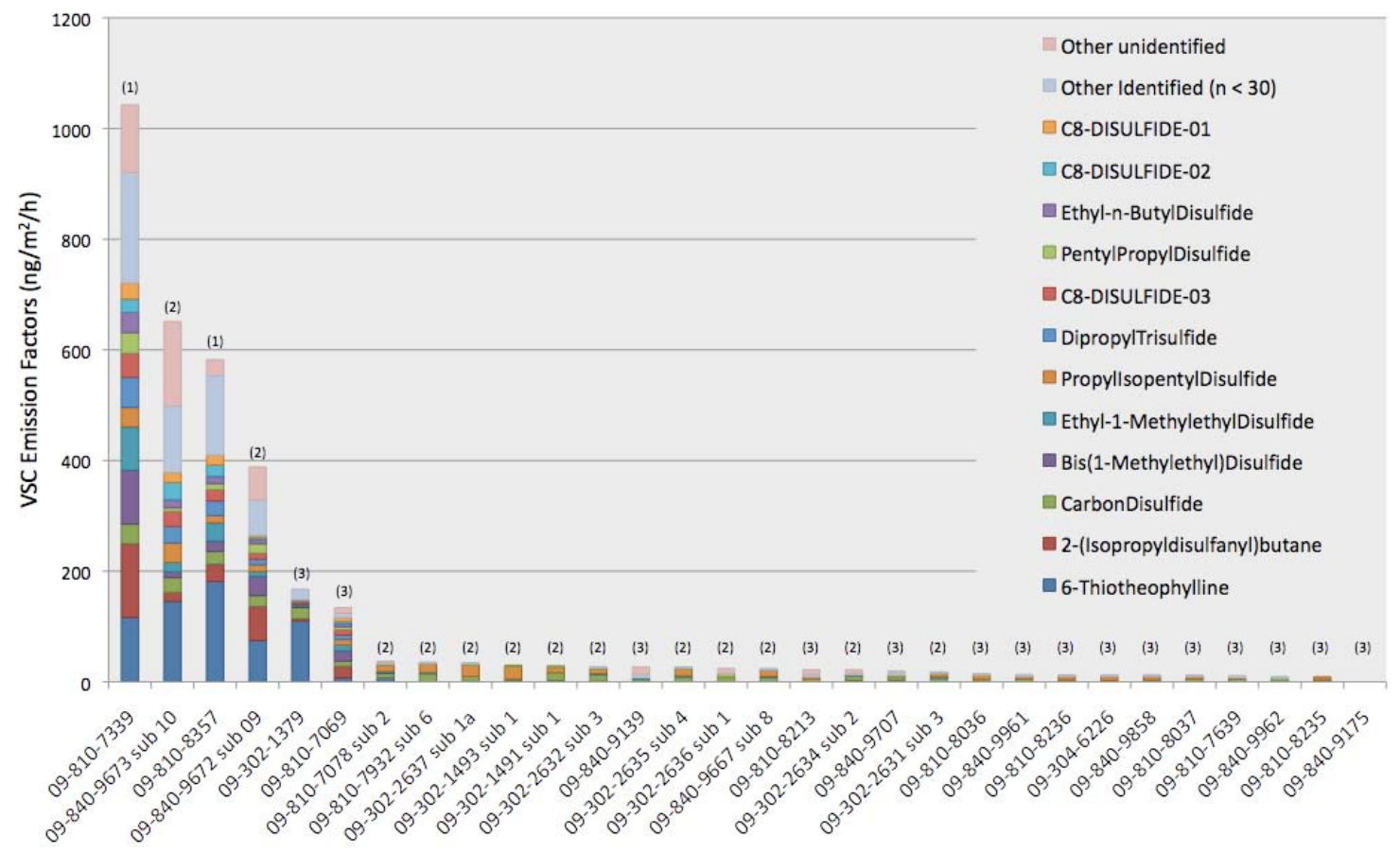

Figure 9: The sum of volatile sulfur (VSC) emissions from the tested samples. The CPSC material tracking number is listed across the category axis, and the legend lists the specific chemicals in the order in which they are stacked. The number in parenthesis above each column indicates the sampling and analysis method used for that sample where (1) indicates that both the SPME-GC/SCD and TD-GC/SCD method were used; (2) indicates that the TD-GC/SCD method was used; and (3) indicates that the SPME-GC/SCD method was used.. Note that the emission factors for the VSCs are reported in units of $n g / \mathrm{m}^{2} / \mathrm{h}$. The 12 chemicals listed capture $>80 \%$ of the chemical mass in the emission stream. The segment in the stacked columns labeled "other identified $(n<30)$ " includes the sum of all remaining identified chemicals in the emissions stream. The top segment includes all remaining unidentified chemicals. 


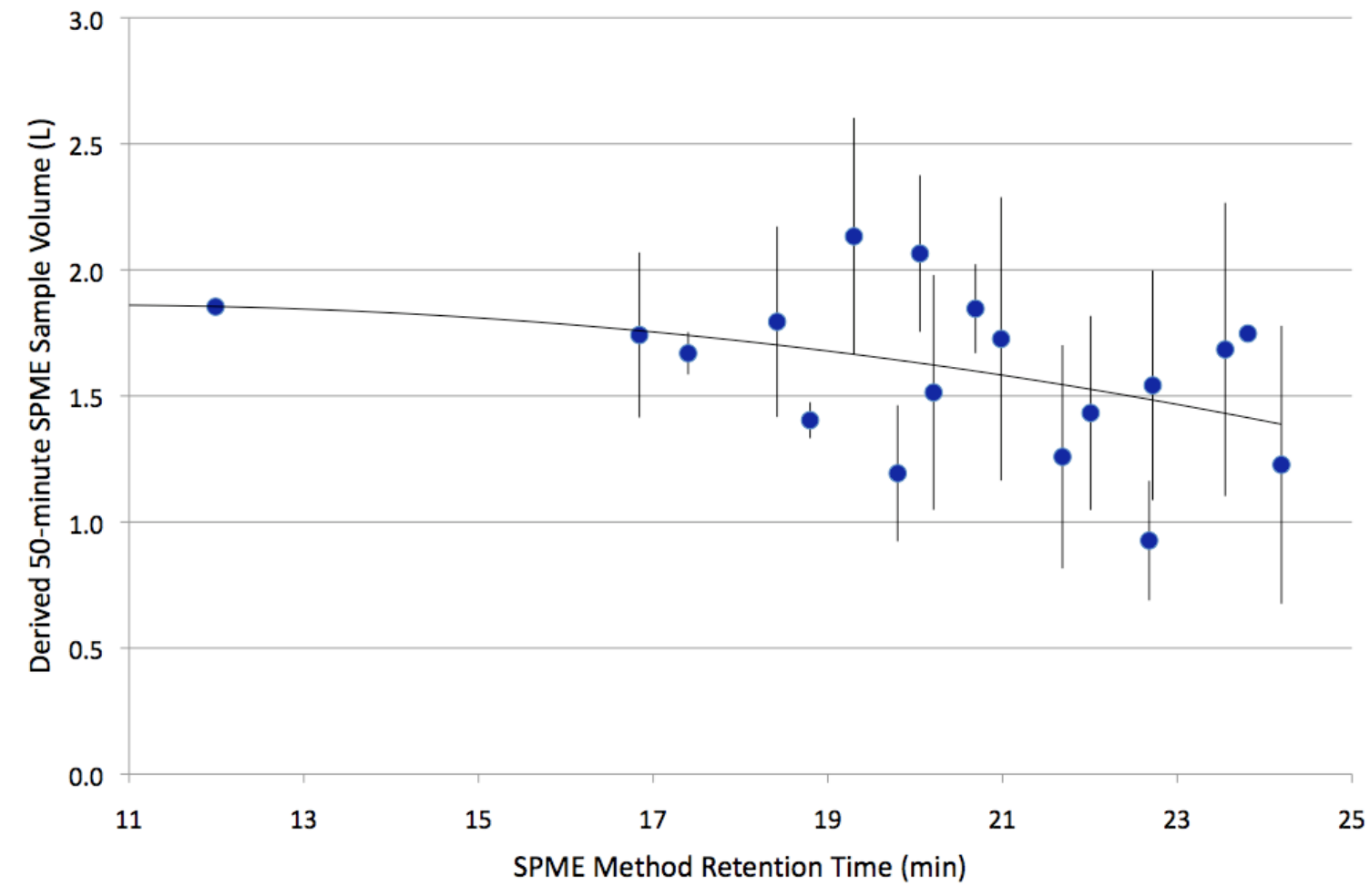

Figure 10: The relationship between the derived sample volume for a 50-minute SPME sample collected from the small chamber under standard conditions is shown across the range of retention times for the measured volatile sulfur chemicals (VSCs) in the emission stream. The data presented here represent 70 sample pairs from five independent measurements collected from two different samples. The line indicating a decreasing trend in sample rate with increasing retention time can be explained by a decrease in chemical diffusivity with increasing molecular size. Because the trend is not significant over the limited range in which most of the measured VSCs elute (between 17 and 24 minutes), the data were used to estimate an average SPME sampling rate for all VSCs. 


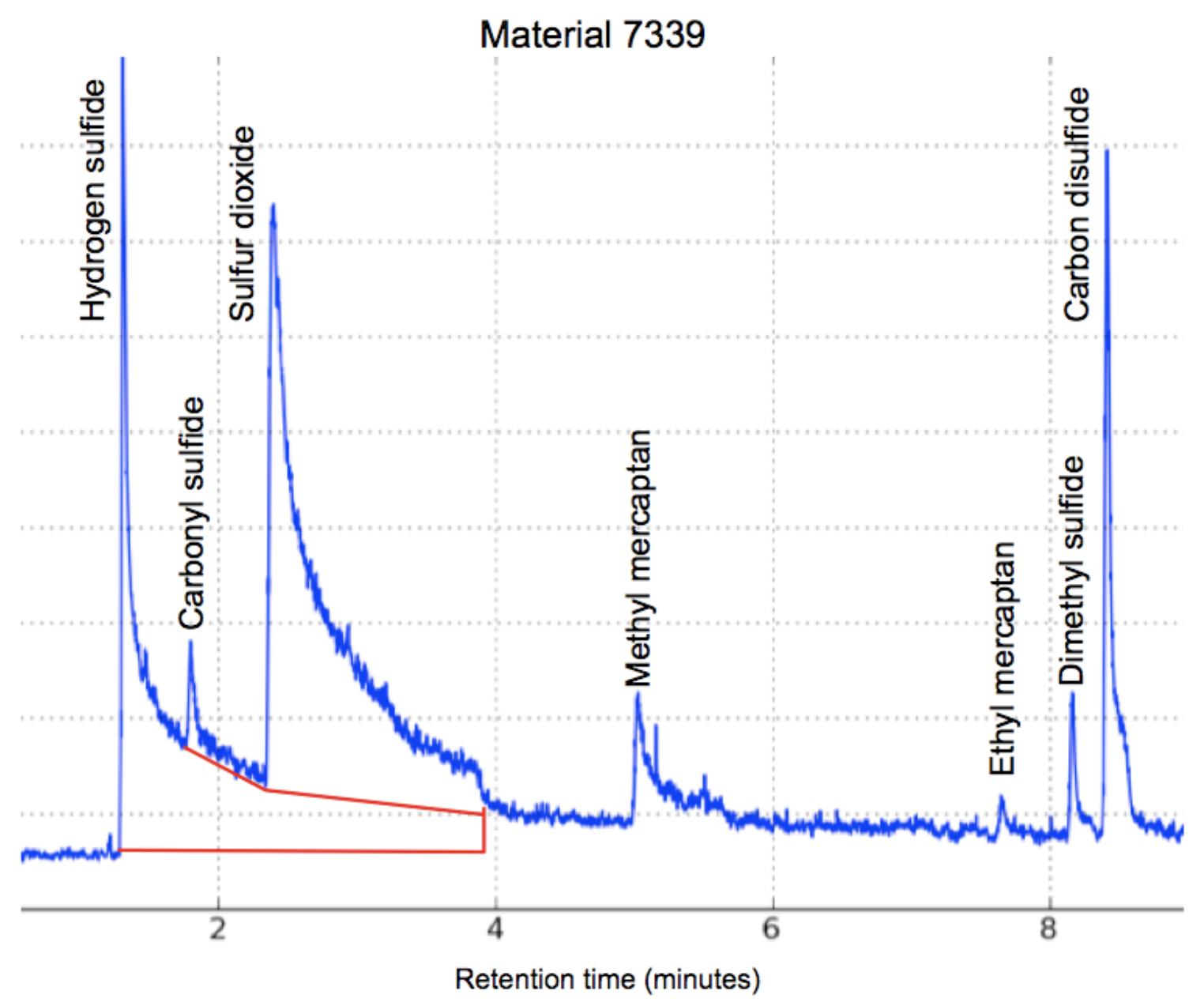

Figure 11: A zoomed region for material 7339 from Figure 7 with each peak identified. Significant tailing in the early eluting chemicals required a tangent skim method for peak integration to resolve the first three chemicals. The baselines for carbonyl sulfide and sulfur dioxide were drawn first as shown to estimate the peak area for each chemical, then a second baseline encompassing all three peaks was drawn and the area for hydrogen sulfide was determined by subtraction. 


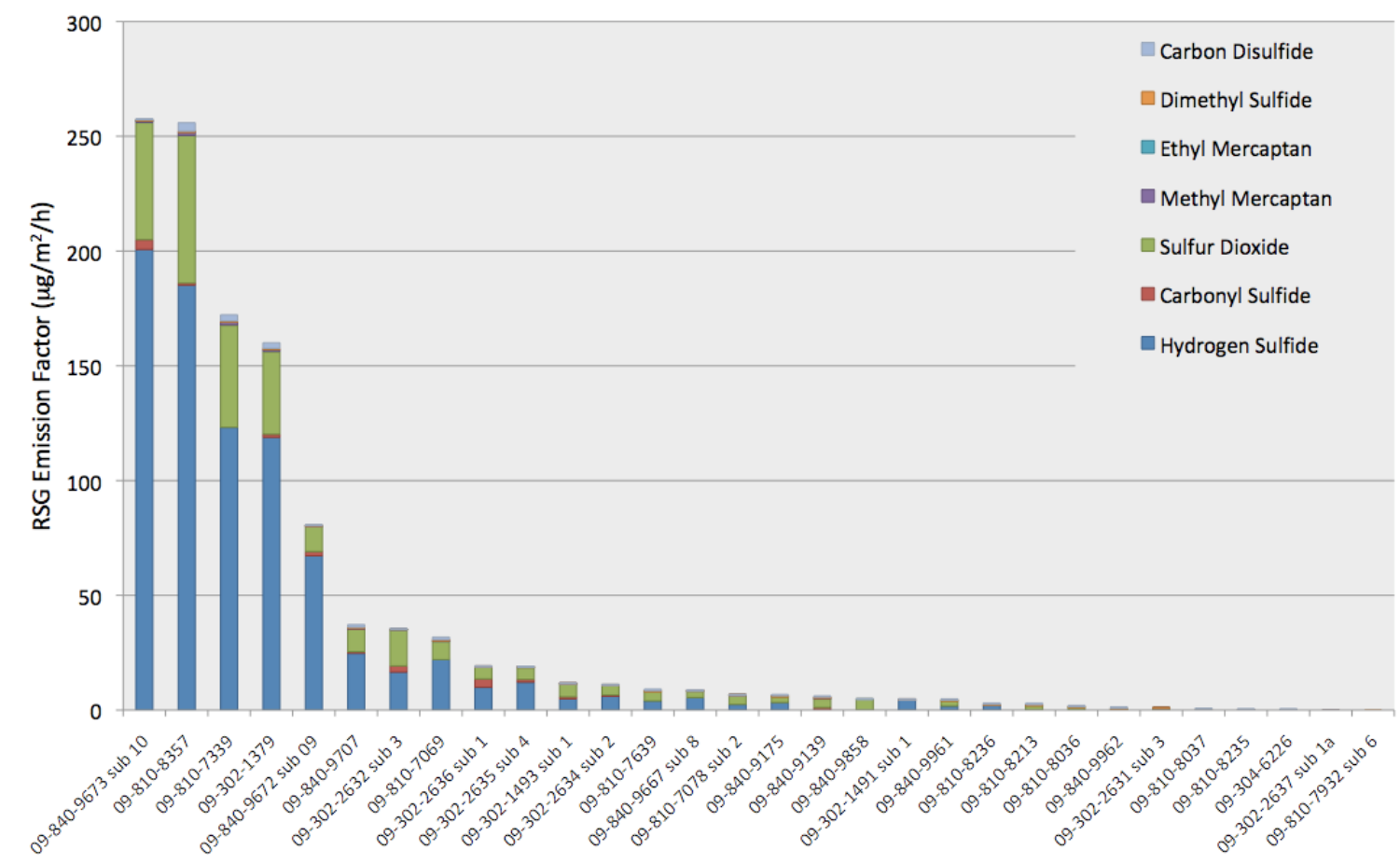

Figure 12: The sum of reactive sulfur gases. The CPSC material tracking number is listed across the category axis, and the legend lists the specific chemicals in the order in which they are stacked. The units are in $\mu \mathrm{g} / \mathrm{m}^{2} / \mathrm{h}$, and actual values are listed in Table 3. 


\section{TABLES}

Table 1: Emission factors $\left(\mu \mathrm{g} / \mathrm{m}^{2} / \mathrm{h}\right)$ for volatile organic chemicals and aldehydes

\begin{tabular}{|c|c|c|c|c|c|}
\hline & 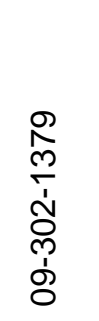 & 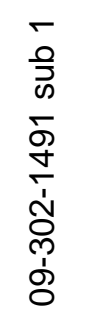 & 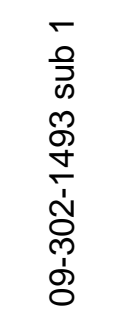 & 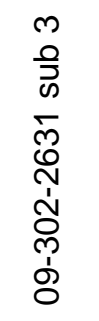 & 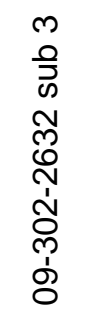 \\
\hline Formaldehyde & 4.40 & 2.20 & 1.57 & 2.01 & 0.60 \\
\hline Acetaldehyde & & & & 0.86 & 1.88 \\
\hline Acetone & 0.83 & & & 2.74 & 0.70 \\
\hline Perfluoro(methylcyclohexane) TIC $^{5}$ & & & & & 0.01 \\
\hline Trichloroethylene & & & & & 0.03 \\
\hline $\begin{array}{l}\text { Toluene } \\
\text { Tetractoroethvlene }\end{array}$ & 0.36 & 0.02 & 0.03 & 0.02 & 0.12 \\
\hline Hexanal & & 0.08 & 0.14 & 0.63 & 0.81 \\
\hline Ethylbenzene & & & & & 0.02 \\
\hline $\begin{array}{l}\mathrm{m} / \mathrm{p} \text {-xylene } \\
\alpha \text {-pinene }\end{array}$ & & & & & 0.05 \\
\hline o-xylene & & & & & 0.02 \\
\hline $\begin{array}{l}\text { Styrene } \\
\text { d-limonene }\end{array}$ & & & & & 0.22 \\
\hline $\begin{array}{l}\text { Benzaldehyde } \\
\text { 1,4-dichlorobenzene }\end{array}$ & 0.06 & 0.10 & 0.16 & 0.29 & 0.19 \\
\hline Octanal & & 0.11 & 0.08 & 0.48 & 0.33 \\
\hline Decamethylcyclopentasiloxane & 0.10 & 0.04 & 0.12 & 0.43 & 0.08 \\
\hline Nonanal & 0.09 & 0.21 & 0.48 & 0.69 & 0.63 \\
\hline Phenol & & & 0.03 & 0.04 & \\
\hline Naphthalene & & & & & 0.02 \\
\hline $\begin{array}{l}\text { Decanal } \\
\alpha \text {-terpineol }\end{array}$ & 0.21 & 0.51 & 0.50 & 0.72 & 0.53 \\
\hline 1-chlorododecane - TIC & & & & 0.07 & 0.27 \\
\hline Butylated hydroxytoluene TIC & 2.86 & 1.81 & 10.25 & 0.20 & 1.35 \\
\hline 1,2,4-trichloro-heptafluorobutane -TIC & & 0.07 & 0.09 & 0.06 & 0.07 \\
\hline $\begin{array}{l}\text { TXIB }^{6} \\
\text { Diethylphthalate }\end{array}$ & & & & & 0.01 \\
\hline
\end{tabular}

\footnotetext{
${ }^{5} \mathrm{~A}$ "- $\mathrm{TIC}$ " at the end of a chemical name indicates that the chemical was quantified based on the total ion chromatogram using the toluene calibration, so the values are reported as toluene equivalents.

${ }^{6}$ 2,2,4-Trimethyl-1,3-pentanediol di-isobutyrate, CAS 6846-50-0.
} 
Table 1 (continued): Emission factors $\left(\mu \mathrm{g} / \mathrm{m}^{2} / \mathrm{h}\right)$ for volatile organic chemicals and aldehydes

\begin{tabular}{|c|c|c|c|c|c|}
\hline & 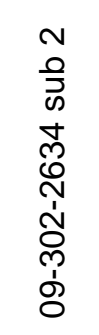 & 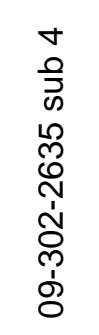 & 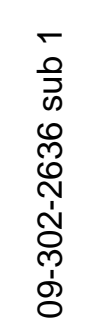 & 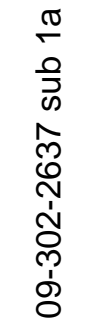 & 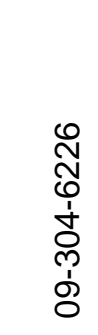 \\
\hline Formaldehyde & 2.49 & 2.12 & 1.37 & 1.66 & 8.04 \\
\hline Acetaldehyde & 0.26 & & 1.07 & 1.20 & 0.81 \\
\hline Acetone & 2.00 & 0.23 & & 0.15 & 0.18 \\
\hline $\begin{array}{l}\text { Perfluoro(methylcyclohexane) TIC } \\
\text { Trichloroethylene }\end{array}$ & & & & & 0.07 \\
\hline $\begin{array}{l}\text { Toluene } \\
\text { Tetrachloroethylene }\end{array}$ & 0.02 & 0.06 & 0.03 & 0.02 & 0.07 \\
\hline $\begin{array}{l}\text { Hexanal } \\
\text { Ethylbenzene }\end{array}$ & 0.82 & 0.83 & 0.42 & 0.24 & 0.01 \\
\hline $\begin{array}{l}\text { m/p-xylene } \\
\alpha \text {-pinene } \\
\text { o-xylene }\end{array}$ & & 0.01 & & & \\
\hline $\begin{array}{l}\text { Styrene } \\
\text { d-limonene }\end{array}$ & & 0.01 & & & \\
\hline $\begin{array}{l}\text { Benzaldehyde } \\
\text { 1,4-dichlorobenzene }\end{array}$ & 0.23 & 0.15 & 0.16 & 0.07 & 0.34 \\
\hline Octanal & 0.76 & 0.32 & 0.45 & 0.10 & 0.31 \\
\hline Decamethylcyclopentasiloxane & 0.03 & 0.04 & 0.19 & 0.04 & 1.98 \\
\hline Nonanal & 1.12 & 0.47 & 0.99 & 0.39 & 0.80 \\
\hline Phenol & & & 0.02 & & 0.08 \\
\hline Naphthalene & & & & & 0.03 \\
\hline $\begin{array}{l}\text { Decanal } \\
\alpha \text {-terpineol }\end{array}$ & 1.38 & 0.44 & 0.42 & 0.40 & 1.70 \\
\hline 1-chlorododecane - TIC & & 2.83 & 1.37 & 6.23 & \\
\hline Butylated hydroxytoluene TIC & 2.06 & 0.21 & 0.76 & 2.95 & 12.39 \\
\hline 1,2,4-trichloro-heptafluorobutane -TIC & & 0.15 & 0.08 & 0.20 & 0.34 \\
\hline $\begin{array}{l}\text { TXIB } \\
\text { Diethylphthalate }\end{array}$ & & & & & 0.02 \\
\hline
\end{tabular}


Table 1 (continued): Emission factors $\left(\mu \mathrm{g} / \mathrm{m}^{2} / \mathrm{h}\right)$ for volatile organic chemicals and aldehydes

\begin{tabular}{|c|c|c|c|c|c|}
\hline & 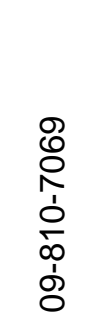 & 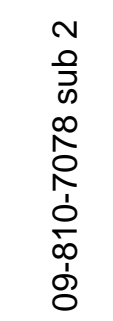 & 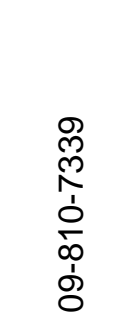 & 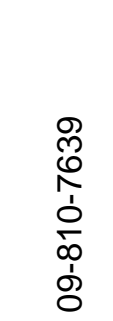 & 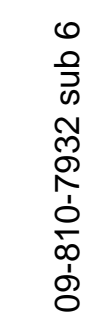 \\
\hline Formaldehyde & 6.06 & 1.21 & 6.75 & 6.62 & 2.11 \\
\hline Acetaldehyde & 0.03 & & & & 0.19 \\
\hline Acetone & 1.02 & 1.83 & 0.51 & 0.15 & 0.07 \\
\hline $\begin{array}{l}\text { Perfluoro(methylcyclohexane) TIC } \\
\text { Trichloroethylene }\end{array}$ & 0.12 & 0.04 & & 0.02 & 0.02 \\
\hline $\begin{array}{l}\text { Toluene } \\
\text { Tetrachloroethylene }\end{array}$ & 0.10 & 0.03 & 0.06 & 0.12 & 0.02 \\
\hline Hexanal & 2.73 & 0.17 & & 2.86 & 0.14 \\
\hline Ethylbenzene & 0.01 & & & 0.01 & \\
\hline $\begin{array}{l}\mathrm{m} / \mathrm{p} \text {-xylene } \\
\alpha \text {-pinene }\end{array}$ & & & & 0.01 & \\
\hline $\begin{array}{l}\text { o-xylene } \\
\text { Styrene }\end{array}$ & & & & & \\
\hline d-limonene & & & & 0.17 & \\
\hline $\begin{array}{l}\text { Benzaldehyde } \\
\text { 1,4-dichlorobenzene }\end{array}$ & 0.42 & 0.17 & 0.18 & 0.43 & 0.07 \\
\hline Octanal & 0.73 & 0.69 & & 0.41 & 0.31 \\
\hline Decamethylcyclopentasiloxane & 0.17 & 0.04 & 0.12 & 0.11 & \\
\hline Nonanal & 0.43 & 0.44 & 0.19 & 0.58 & 0.38 \\
\hline Phenol & 0.01 & 0.04 & 0.04 & & \\
\hline Naphthalene & 0.02 & & & 0.03 & \\
\hline $\begin{array}{l}\text { Decanal } \\
\alpha \text {-terpineol }\end{array}$ & 0.54 & 0.50 & 0.24 & 0.86 & 0.33 \\
\hline 1-chlorododecane - TIC & 0.08 & 10.94 & 0.97 & & \\
\hline Butylated hydroxytoluene TIC & 0.64 & 0.76 & 14.33 & 10.50 & 18.71 \\
\hline 1,2,4-trichloro-heptafluorobutane -TIC & 0.06 & 0.13 & & 0.15 & \\
\hline TXIB & & & & 0.02 & \\
\hline Diethylphthalate & & & & & \\
\hline
\end{tabular}


Table 1 (continued): Emission factors $\left(\mu \mathrm{g} / \mathrm{m}^{2} / \mathrm{h}\right)$ for volatile organic chemicals and aldehydes

\begin{tabular}{|c|c|c|c|c|c|}
\hline & 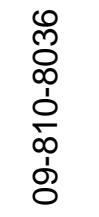 & $\begin{array}{l}\hat{m} \\
\varnothing \\
\infty \\
o \\
o \\
\infty \\
o \\
\text { od }\end{array}$ & 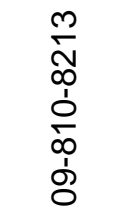 & 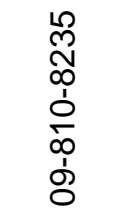 & 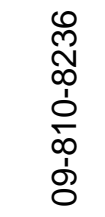 \\
\hline Formaldehyde & 7.98 & 7.54 & 15.87 & 8.02 & 5.57 \\
\hline Acetaldehyde & 1.16 & & 0.47 & 0.78 & \\
\hline Acetone & 0.43 & 0.80 & 1.13 & 0.48 & \\
\hline $\begin{array}{l}\text { Perfluoro(methylcyclohexane) TIC } \\
\text { Trichloroethylene }\end{array}$ & & 0.35 & & & \\
\hline $\begin{array}{l}\text { Toluene } \\
\text { Tetrachloroethylene }\end{array}$ & 0.02 & 0.09 & 0.18 & 0.09 & 0.07 \\
\hline Hexanal & 0.20 & 0.73 & 0.86 & 0.81 & 0.47 \\
\hline $\begin{array}{l}\text { Ethylbenzene } \\
\mathrm{m} / \mathrm{p} \text {-xylene }\end{array}$ & & & $\begin{array}{l}0.01 \\
0.02\end{array}$ & 0.01 & \\
\hline $\begin{array}{l}\alpha \text {-pinene } \\
\text { o-xylene }\end{array}$ & & & & & \\
\hline $\begin{array}{l}\text { Styrene } \\
\text { d-limonene }\end{array}$ & & 0.01 & 0.01 & & \\
\hline $\begin{array}{l}\text { Benzaldehyde } \\
\text { 1,4-dichlorobenzene }\end{array}$ & 0.12 & 0.34 & 0.33 & 0.19 & 0.38 \\
\hline Octanal & 0.13 & 0.18 & 0.31 & 0.14 & 0.23 \\
\hline Decamethylcyclopentasiloxane & 0.06 & 0.18 & 0.16 & 0.14 & 0.13 \\
\hline Nonanal & 0.37 & 0.21 & 0.51 & 0.50 & 0.67 \\
\hline Phenol & & & 0.03 & & \\
\hline Naphthalene & & & 0.01 & & \\
\hline $\begin{array}{l}\text { Decanal } \\
\alpha \text {-terpineol }\end{array}$ & 0.54 & 0.24 & 1.19 & 0.80 & 0.53 \\
\hline 1-chlorododecane - TIC & 0.02 & & & & \\
\hline Butylated hydroxytoluene TIC & 3.04 & 2.97 & 12.23 & 20.13 & 23.35 \\
\hline 1,2,4-trichloro-heptafluorobutane -TIC & 0.04 & 0.44 & 0.12 & 0.17 & 0.29 \\
\hline $\begin{array}{l}\text { TXIB } \\
\text { Diethylphthalate }\end{array}$ & & 0.01 & 0.02 & & \\
\hline
\end{tabular}


Table 1 (continued): Emission factors $\left(\mu \mathrm{g} / \mathrm{m}^{2} / \mathrm{h}\right)$ for volatile organic chemicals and aldehydes

\begin{tabular}{|c|c|c|c|c|c|}
\hline & 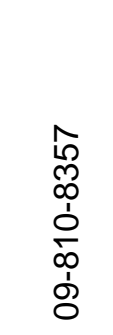 & 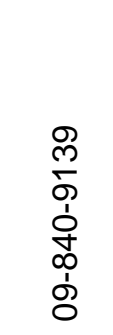 & 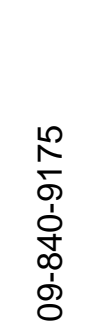 & 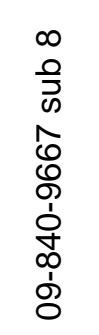 & 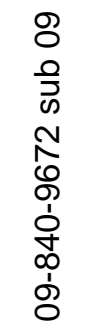 \\
\hline Formaldehyde & 7.34 & 11.39 & 4.81 & 0.88 & 0.57 \\
\hline Acetaldehyde & & 0.27 & & 1.50 & \\
\hline Acetone & 0.52 & 1.00 & 1.13 & 0.51 & \\
\hline $\begin{array}{l}\text { Perfluoro(methylcyclohexane) TIC } \\
\text { Trichloroethylene }\end{array}$ & & 0.09 & 0.10 & 0.15 & 0.04 \\
\hline $\begin{array}{l}\text { Toluene } \\
\text { Tetrachloroethylene }\end{array}$ & 0.32 & 0.06 & 0.16 & 0.02 & 0.02 \\
\hline Hexanal & 0.14 & 3.75 & 7.72 & 1.57 & 0.18 \\
\hline Ethylbenzene & 0.06 & & 0.02 & & \\
\hline m/p-xylene & 0.15 & & 0.06 & & \\
\hline$\alpha$-pinene & 0.03 & & & & \\
\hline o-xylene & 0.10 & & & & \\
\hline $\begin{array}{l}\text { Styrene } \\
\text { d-limonene }\end{array}$ & 0.01 & & 0.01 & & \\
\hline $\begin{array}{l}\text { Benzaldehyde } \\
\text { 1,4-dichlorobenzene }\end{array}$ & 0.67 & 0.29 & 0.53 & 0.24 & 0.16 \\
\hline Octanal & 0.34 & 0.17 & 0.52 & 0.32 & 0.17 \\
\hline Decamethylcyclopentasiloxane & 0.23 & 0.18 & 0.11 & 0.02 & 0.07 \\
\hline Nonanal & 0.64 & 0.12 & 0.45 & 0.22 & 0.18 \\
\hline Phenol & 0.01 & & & & \\
\hline Naphthalene & 0.01 & & 0.01 & & \\
\hline $\begin{array}{l}\text { Decanal } \\
\alpha \text {-terpineol }\end{array}$ & $\begin{array}{l}0.50 \\
0.01\end{array}$ & 0.25 & 0.71 & 0.20 & 0.13 \\
\hline 1-chlorododecane - TIC & 0.67 & & 0.04 & 0.34 & 0.66 \\
\hline Butylated hydroxytoluene TIC & 11.79 & 1.44 & 0.13 & 0.53 & 7.30 \\
\hline 1,2,4-trichloro-heptafluorobutane -TIC & 0.23 & 0.08 & 0.12 & 0.12 & 0.07 \\
\hline TXIB & 0.03 & & & & \\
\hline Diethylphthalate & 0.08 & & & & \\
\hline
\end{tabular}


Table 1 (continued): Emission factors $\left(\mu \mathrm{g} / \mathrm{m}^{2} / \mathrm{h}\right)$ for volatile organic chemicals and aldehydes

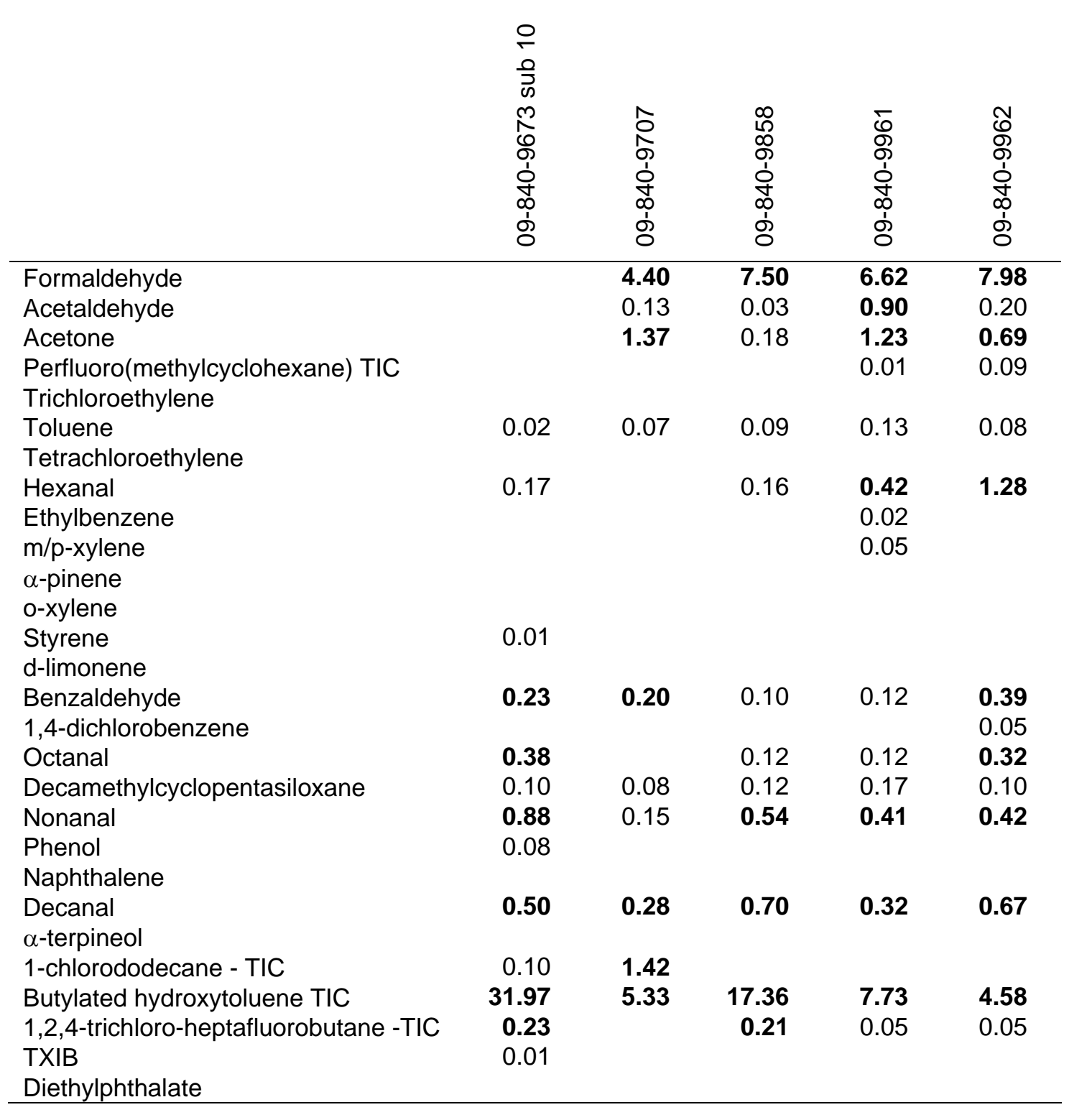


Table 2: Emission factors $\left(\mathrm{ng} / \mathrm{m}^{2} / \mathrm{h}\right)$ for volatile sulfur chemicals

\begin{tabular}{|c|c|c|c|c|c|}
\hline & 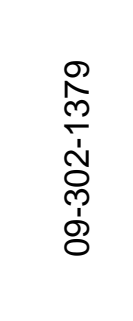 & 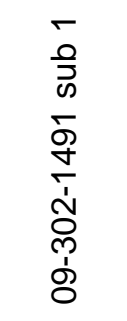 & 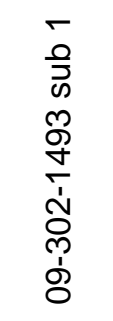 & 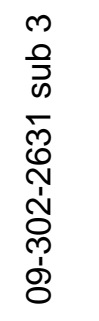 & 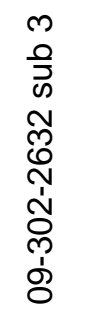 \\
\hline $\begin{array}{l}\text { Isopropyl Mercaptan-PS' } \\
\text { tert-Butyl Mercaptan-PS } \\
\text { 1-Propanethiol-PS } \\
\text { tert-Amyl Mercaptan-PS }\end{array}$ & 2.62 & & & & \\
\hline $\begin{array}{l}\text { Dimethyl Disulfide-PS } \\
\text { sec-Butyl Mercaptan } \\
\text { 1-Pentanethiol-PS } \\
\text { 1,3-Propanedithiol }\end{array}$ & 6.00 & & & & \\
\hline $\begin{array}{l}\text { Methyl Isopropyl Disulfide } \\
\text { di-n-PropylSulfide-PS } \\
\text { Diethyl Disulfide-PS } \\
\text { Methyl Propyl Disulfide-PS }\end{array}$ & & & & & 1.05 \\
\hline Ethyl-1-Methylethyl Disulfide & 2.71 & & & 0.68 & 0.65 \\
\hline $\begin{array}{l}\text { Methyl-n-Butyl Disulfide } \\
\text { 1,1-Dimethylethyl Ethyl Disulfide } \\
\text { Ethyl-n-Propyl Disulfide }\end{array}$ & & & & 1.27 & 1.52 \\
\hline $\begin{array}{l}\text { Bis(1-Methylethyl)Disulfide } \\
\text { (1-Methylethyl)(1,1-Dimethylethyl)Disulfide } \\
\text { 1-Methylethyl Propyl Disulfide }\end{array}$ & 2.58 & & & & \\
\hline Ethyl-n-Butyl Disulfide & 1.88 & & & & \\
\hline Di-n-butyl Sulfide-PS & 2.19 & & & & \\
\hline Dipropyl Disulfide-PS & 2.51 & & & & \\
\hline $\begin{array}{l}\text { 2-(Isopropyldisulfanyl)butane } \\
\text { Ethyllsopentyl Disulfide }\end{array}$ & 3.73 & & & & \\
\hline $\begin{array}{l}\text { C8-DISULFIDE-01 } \\
\text { Propyl-n-Butyl Disulfide }\end{array}$ & 2.66 & & & & \\
\hline C8-DISULFIDE-02 & 2.13 & & & & \\
\hline o-(Propylthio)-Phenol & & & & & \\
\hline Propyl Isopentyl Disulfide & & 10.12 & 22.85 & 7.20 & 8.48 \\
\hline Pentyl Propyl Disulfide & & 2.15 & 2.15 & 0.81 & 1.67 \\
\hline C8-DISULFIDE-03 & 3.02 & & & & \\
\hline C8-DISULFIDE-04 & & & & & \\
\hline Pentyl(1-methylethyl)Disulfide & & & & & \\
\hline $\begin{array}{l}\text { Benzothiazole } \\
\text { Dinronvl Trisulfide }\end{array}$ & & & & & \\
\hline $\begin{array}{l}\text { n-Propyl-n-Hexyl Disulfide } \\
\text { 2-[(2-Methylpropyl)thiol]-Phenol } \\
\text { n-Butyl-n-Pentyl Disulfide }\end{array}$ & & & & & \\
\hline $\begin{array}{l}\text { 6-Thiotheophylline } \\
\text { CyclicOctaatomicSulfur }\end{array}$ & $\begin{array}{r}110.36 \\
5.21\end{array}$ & 2.49 & 3.37 & & 0.96 \\
\hline
\end{tabular}

\footnotetext{
${ }^{7} \mathrm{~A}$ "-PS" at the end of a chemical name indicates that it was identified using a pure standard.
} 
Table 2 (continued): Emission factors $\left(\mathrm{ng} / \mathrm{m}^{2} / \mathrm{h}\right)$ for volatile sulfur chemicals

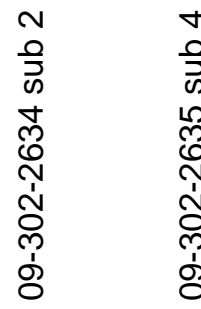

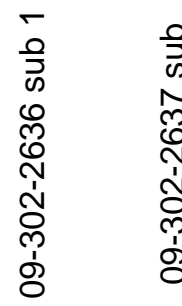

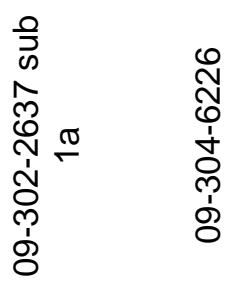

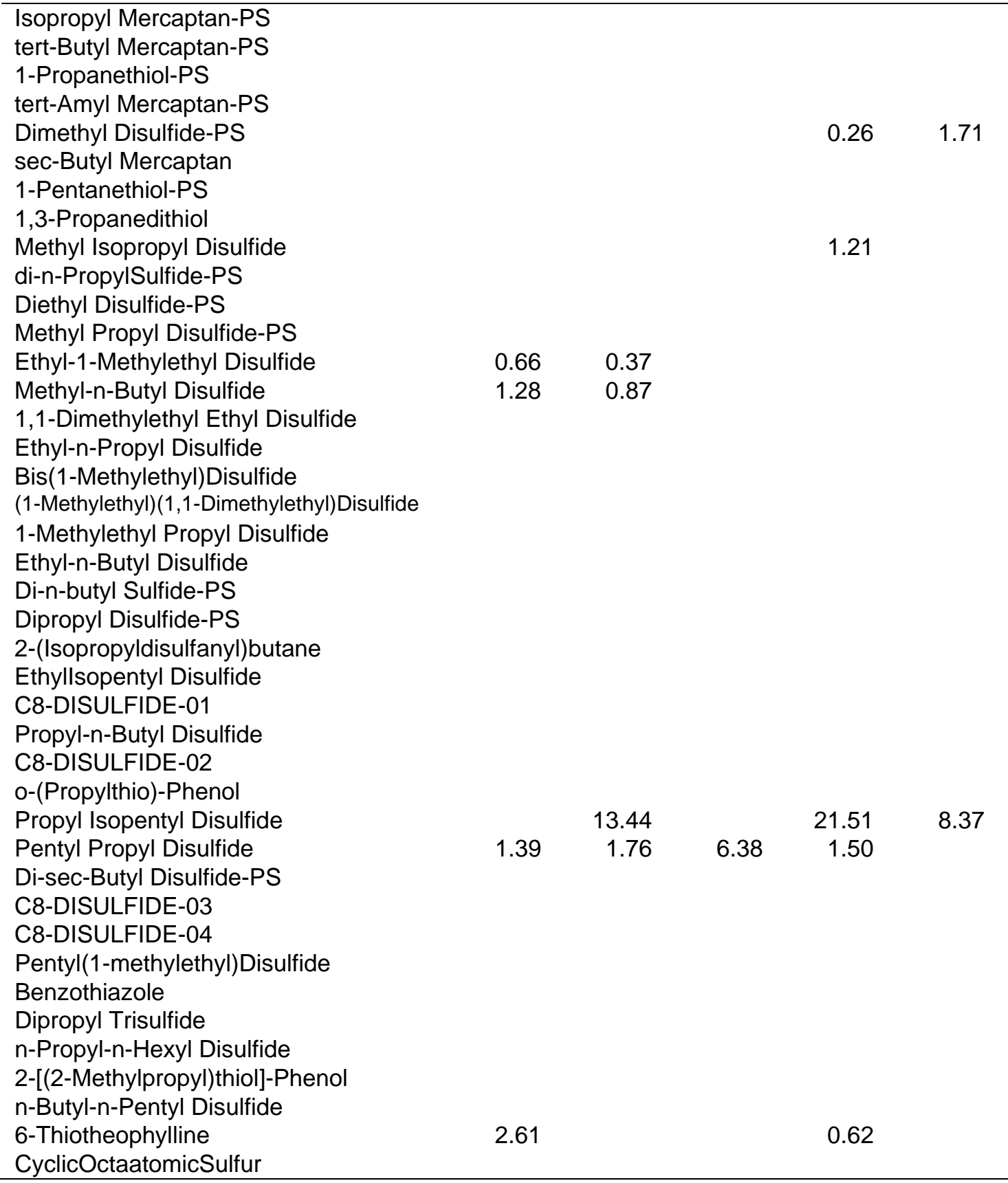


Table 2 (continued): Emission factors $\left(\mathrm{ng} / \mathrm{m}^{2} / \mathrm{h}\right)$ for volatile sulfur chemicals

\begin{tabular}{|c|c|c|c|c|c|}
\hline & 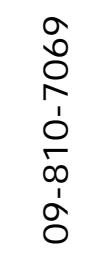 & 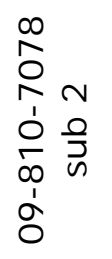 & 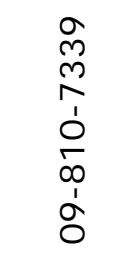 & 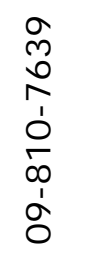 & 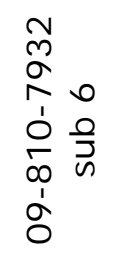 \\
\hline Isopropyl Mercaptan-PS & 1.17 & & 3.93 & & \\
\hline tert-Butyl Mercaptan-PS & & & 0.70 & & \\
\hline 1-Propanethiol-PS & & & 1.23 & & \\
\hline tert-Amyl Mercaptan-PS & & & 0.77 & & \\
\hline Dimethyl Disulfide-PS & 4.27 & & 3.07 & 3.53 & \\
\hline sec-Butyl Mercaptan & & & 0.74 & & \\
\hline 1-Pentanethiol-PS & & & 0.31 & & \\
\hline 1,3-Propanedithiol & & & 2.21 & & \\
\hline Methyl Isopropyl Disulfide & 2.76 & 1.78 & 18.34 & & \\
\hline di-n-PropylSulfide-PS & & 0.64 & & & \\
\hline Diethyl Disulfide-PS & & & 8.74 & & \\
\hline Methyl Propyl Disulfide-PS & & 0.15 & 1.20 & & \\
\hline Ethyl-1-Methylethyl Disulfide & 11.11 & 1.27 & 78.11 & & 0.56 \\
\hline Methyl-n-Butyl Disulfide & & 0.48 & 13.82 & & 1.05 \\
\hline 1,1-Dimethylethyl Ethyl Disulfide & & & 5.05 & & \\
\hline Ethyl-n-Propyl Disulfide & & & 3.29 & & \\
\hline Bis(1-Methylethyl)Disulfide & 18.24 & 0.24 & 97.75 & & \\
\hline (1-Methylethyl)(1,1-Dimethylethyl)Disulfide & & & 1.98 & & \\
\hline 1-Methylethyl Propyl Disulfide & & & 15.74 & & \\
\hline Ethyl-n-Butyl Disulfide & 6.05 & & 36.21 & & \\
\hline Di-n-butyl Sulfide-PS & & & 16.47 & & \\
\hline Dipropyl Disulfide-PS & & & 6.61 & & \\
\hline 2-(Isopropyldisulfanyl)butane & 20.96 & & 133.14 & & \\
\hline Ethyllsopentyl Disulfide & & & 5.53 & & \\
\hline C8-DISULFIDE-01 & 6.80 & & 29.16 & & \\
\hline Propyl-n-Butyl Disulfide & & & 5.45 & & \\
\hline C8-DISULFIDE-02 & 3.75 & & 24.17 & & \\
\hline o-(Propylthio)-Phenol & & & 2.92 & & \\
\hline Propyl Isopentyl Disulfide & 9.55 & 12.14 & 35.10 & 2.08 & 16.02 \\
\hline Pentyl Propyl Disulfide & 5.43 & 1.36 & 37.55 & & 2.04 \\
\hline \multicolumn{6}{|l|}{ Di-sec-Butyl Disulfide-PS } \\
\hline C8-DISULFIDE-03 & 9.55 & & 43.60 & & \\
\hline C8-DISULFIDE-04 & & & 10.40 & & \\
\hline Pentyl(1-methylethyl)Disulfide & & & 15.36 & & \\
\hline Benzothiazole & & & 24.34 & & \\
\hline Dipropyl Trisulfide & 7.84 & & 54.23 & & \\
\hline n-Propyl-n-Hexyl Disulfide & & & 9.23 & & \\
\hline 2-[(2-Methylpropyl)thiol]-Phenol & & & 12.39 & & \\
\hline n-Butyl-n-Pentyl Disulfide & & & 19.18 & & \\
\hline 6-Thiotheophylline & 7.25 & 7.73 & 116.48 & & \\
\hline CyclicOctaatomicSulfur & & & 7.33 & & \\
\hline
\end{tabular}


Table 2 (continued): Emission factors $\left(\mathrm{ng} / \mathrm{m}^{2} / \mathrm{h}\right)$ for volatile sulfur chemicals

\begin{tabular}{|c|c|c|c|}
\hline 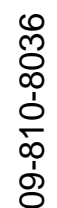 & 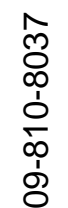 & 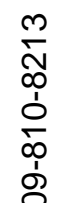 & 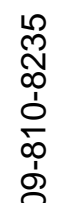 \\
\hline
\end{tabular}

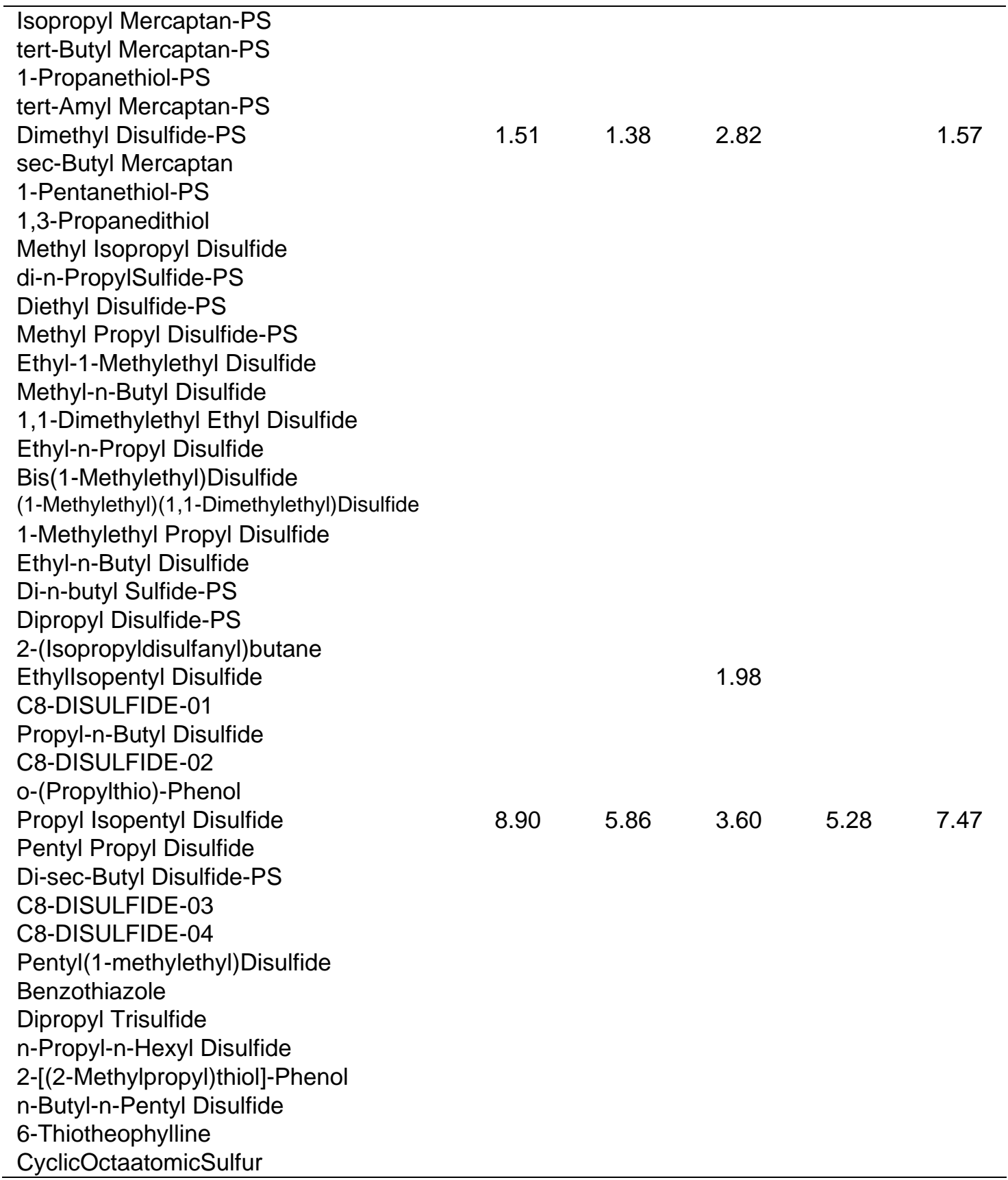


Table 2 (continued): Emission factors $\left(\mathrm{ng} / \mathrm{m}^{2} / \mathrm{h}\right)$ for volatile sulfur chemicals

\begin{tabular}{|c|c|c|c|c|c|}
\hline & $\begin{array}{l}\hat{L} \\
m \\
\infty \\
0 \\
0 \\
0 \\
\infty \\
0 \\
0 \\
0\end{array}$ & 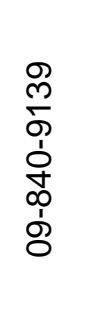 & 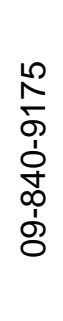 & $\begin{array}{l}\infty \\
0 \\
0 \\
0 \\
\hat{0} \\
0 \\
0 \\
0 \\
+ \\
\infty \\
0 \\
0 \\
0\end{array}$ & 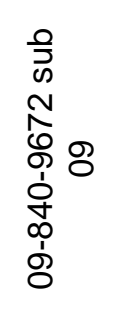 \\
\hline Isopropyl Mercaptan-PS & 5.40 & & & & 1.20 \\
\hline tert-Butyl Mercaptan-PS & 0.51 & & & & \\
\hline 1-Propanethiol-PS & 2.94 & & & & \\
\hline tert-Amyl Mercaptan-PS & 1.74 & & & & \\
\hline Dimethyl Disulfide-PS & 6.63 & 5.98 & & & \\
\hline sec-Butyl Mercaptan & 0.68 & & & & \\
\hline 1-Pentanethiol-PS & 0.54 & & & & \\
\hline 1,3-Propanedithiol & 1.97 & & & & 0.89 \\
\hline $\begin{array}{l}\text { Methyl Isopropyl Disulfide } \\
\text { di-n-PropylSulfide-PS }\end{array}$ & 4.94 & & & & 10.94 \\
\hline Diethyl Disulfide-PS & 7.15 & & & & 0.51 \\
\hline Methyl Propyl Disulfide-PS & & & & & 0.48 \\
\hline Ethyl-1-Methylethyl Disulfide & 32.97 & 2.97 & & 0.63 & 8.64 \\
\hline Methyl-n-Butyl Disulfide & 2.14 & & & 1.24 & 12.42 \\
\hline 1,1-Dimethylethyl Ethyl Disulfide & 2.86 & & & & 0.81 \\
\hline Ethyl-n-Propyl Disulfide & 6.17 & & & & 0.72 \\
\hline Bis(1-Methylethyl)Disulfide & 18.89 & & & & 35.07 \\
\hline (1-Methylethyl)(1,1-Dimethylethyl)Disulfide & 1.12 & & & & 0.52 \\
\hline 1-Methylethyl Propyl Disulfide & 5.98 & & & & 3.18 \\
\hline Ethyl-n-Butyl Disulfide & 13.04 & & & & 7.49 \\
\hline Di-n-butyl Sulfide-PS & 17.50 & & & & 4.14 \\
\hline Dipropyl Disulfide-PS & 4.42 & & & & 5.38 \\
\hline 2-(Isopropyldisulfanyl)butane & 25.39 & & & & 61.42 \\
\hline Ethyllsopentyl Disulfide & 17.38 & & & & \\
\hline C8-DISULFIDE-01 & 18.09 & & & & 4.28 \\
\hline Propyl-n-Butyl Disulfide & 3.07 & & & & 3.22 \\
\hline C8-DISULFIDE-02 & 20.73 & & & & 3.07 \\
\hline o-(Propylthio)-Phenol & 0.75 & & & & 2.06 \\
\hline Propyl Isopentyl Disulfide & 13.07 & & & 10.90 & 12.10 \\
\hline Pentyl Propyl Disulfide & 10.64 & & & 1.81 & 17.43 \\
\hline \multicolumn{6}{|l|}{ Di-sec-Butyl Disulfide-PS } \\
\hline C8-DISULFIDE-03 & 20.55 & & & & 10.48 \\
\hline C8-DISULFIDE-04 & 9.05 & & & & 1.34 \\
\hline Pentyl(1-methylethyl)Disulfide & 16.23 & & & & 1.82 \\
\hline Benzothiazole & 15.74 & & & & 7.07 \\
\hline Dipropyl Trisulfide & 26.54 & & & & 10.14 \\
\hline n-Propyl-n-Hexyl Disulfide & 7.49 & & & & 2.63 \\
\hline 2-[(2-Methylpropyl)thiol]-Phenol & 9.35 & & & & 1.98 \\
\hline n-Butyl-n-Pentyl Disulfide & 6.57 & & & & 2.25 \\
\hline 6-Thiotheophylline & 181.44 & & & & 74.90 \\
\hline CyclicOctaatomicSulfur & 12.67 & & & & \\
\hline
\end{tabular}


Table 2 (continued): Emission factors $\left(\mathrm{ng} / \mathrm{m}^{2} / \mathrm{h}\right)$ for volatile sulfur chemicals

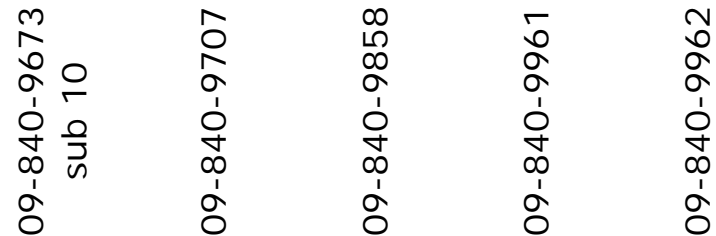

\begin{tabular}{|c|c|c|c|c|c|}
\hline Isopropyl Mercaptan-PS & 2.16 & & & & \\
\hline tert-Butyl Mercaptan-PS & 0.64 & & & & \\
\hline 1-Propanethiol-PS & 0.44 & & & & \\
\hline tert-Amyl Mercaptan-PS & 0.65 & & & & \\
\hline Dimethyl Disulfide-PS & 0.37 & 5.18 & 2.01 & 3.89 & 2.06 \\
\hline sec-Butyl Mercaptan & 0.40 & & & & \\
\hline 1-Pentanethiol-PS & 0.63 & & & & \\
\hline 1,3-Propanedithiol & 1.33 & & & & \\
\hline $\begin{array}{l}\text { Methyl Isopropyl Disulfide } \\
\text { di-n-PropyISulfide-PS }\end{array}$ & 2.31 & & & & \\
\hline Diethyl Disulfide-PS & 4.36 & & & & \\
\hline Methyl Propyl Disulfide-PS & 0.60 & & & & \\
\hline Ethyl-1-Methylethyl Disulfide & 16.87 & & & & \\
\hline Methyl-n-Butyl Disulfide & 1.97 & & & & \\
\hline 1,1-Dimethylethyl Ethyl Disulfide & 4.85 & & & & \\
\hline Ethyl-n-Propyl Disulfide & 1.01 & & & & \\
\hline Bis(1-Methylethyl)Disulfide & 10.55 & & & & \\
\hline (1-Methylethyl)(1,1-Dimethylethyl)Disulfide & 2.63 & & & & \\
\hline 1-Methylethyl Propyl Disulfide & 6.96 & & & & \\
\hline Ethyl-n-Butyl Disulfide & 14.36 & & & & \\
\hline Di-n-butyl Sulfide-PS & 1.02 & & & & \\
\hline Dipropyl Disulfide-PS & 1.18 & & & & \\
\hline 2-(Isopropyldisulfanyl)butane & 16.41 & & & & \\
\hline Ethyllsopentyl Disulfide & 9.65 & & & & \\
\hline C8-DISULFIDE-01 & 17.85 & & & & \\
\hline Propyl-n-Butyl Disulfide & 3.67 & & & & \\
\hline C8-DISULFIDE-02 & 31.37 & & & & \\
\hline o-(Propylthio)-Phenol & 1.35 & & & & \\
\hline Propyl Isopentyl Disulfide & 35.38 & 0.95 & 7.27 & 4.45 & \\
\hline Pentyl Propyl Disulfide & 6.56 & 0.47 & & & 3.73 \\
\hline Di-sec-Butyl Disulfide-PS & 8.84 & & & & \\
\hline C8-DISULFIDE-03 & 27.30 & & & & \\
\hline C8-DISULFIDE-04 & 12.05 & & & & \\
\hline Pentyl(1-methylethyl)Disulfide & 19.08 & & & & \\
\hline Benzothiazole & 8.53 & & & & \\
\hline Dipropyl Trisulfide & 29.69 & & & & \\
\hline n-Propyl-n-Hexyl Disulfide & 7.67 & & & & \\
\hline 2-[(2-Methylpropyl)thiol]-Phenol & 8.83 & & & & \\
\hline n-Butyl-n-Pentyl Disulfide & 6.94 & & & & \\
\hline 6-Thiotheophylline & 145.40 & 2.73 & & & \\
\hline CyclicOctaatomicSulfur & & & & & \\
\hline
\end{tabular}


Table 3. Emission factors $\left(\mu \mathrm{g} / \mathrm{m}^{2} / \mathrm{h}\right)$ for reactive sulfur gases

\begin{tabular}{|c|c|c|c|c|c|c|c|}
\hline & $\begin{array}{l}\frac{0}{0} \\
\frac{0}{5} \\
0 \\
0 \\
\frac{c}{0} \\
\frac{0}{0} \\
\frac{0}{0} \\
\text { 齐 }\end{array}$ & 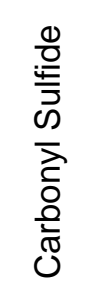 & 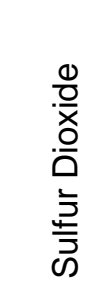 & 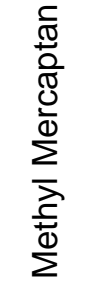 & 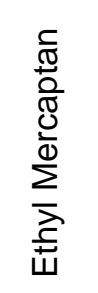 & 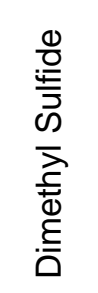 & 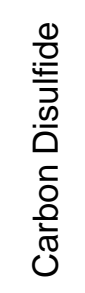 \\
\hline $09-302-1379$ & 118.83 & 1.35 & 36.09 & 0.93 & & 0.40 & 2.44 \\
\hline 09-302-1491 sub 1 & 4.60 & & & 0.27 & & 0.02 & 0.05 \\
\hline 09-302-1493 sub 1 & 4.86 & 0.90 & 5.89 & 0.25 & & 0.01 & 0.04 \\
\hline 09-302-2631 sub 3 & & & 1.13 & 0.04 & & 0.01 & \\
\hline 09-302-2632 sub 3 & 16.56 & 2.70 & 15.73 & 0.46 & 0.03 & 0.01 & 0.12 \\
\hline 09-302-2634 sub 2 & 6.33 & 0.27 & 4.58 & & & 0.01 & 0.08 \\
\hline 09-302-2635 sub 4 & 12.13 & 1.21 & 5.50 & 0.22 & & 0.01 & 0.08 \\
\hline 09-302-2636 sub 1 & 9.96 & 3.62 & 5.21 & 0.40 & & 0.02 & 0.08 \\
\hline 09-302-2637 sub 1a & & & & 0.02 & & 0.00 & 0.02 \\
\hline $09-304-6226$ & & & & & & 0.18 & 0.45 \\
\hline 09-810-7069 & 22.04 & & 8.13 & 0.27 & & 0.31 & 1.08 \\
\hline 09-810-7078 sub 2 & 2.45 & & 4.37 & 0.02 & & 0.01 & 0.02 \\
\hline 09-810-7339 & 123.16 & & 44.60 & 1.33 & & 0.44 & 2.70 \\
\hline 09-810-7639 & 3.99 & & 4.24 & & & 0.24 & 0.72 \\
\hline 09-810-7932 sub 6 & & & & & & 0.00 & \\
\hline 09-810-8036 & & & 1.36 & & & 0.23 & 0.48 \\
\hline 09-810-8037 & & & & & & 0.18 & 0.69 \\
\hline 09-810-8213 & & & 2.00 & & & 0.31 & 0.67 \\
\hline 09-810-8235 & 0.12 & & & & & 0.16 & 0.36 \\
\hline 09-810-8236 & 2.39 & & & & & 0.15 & 0.48 \\
\hline 09-810-8357 & 185.14 & 0.87 & 64.36 & 1.47 & & 0.36 & 3.67 \\
\hline 09-840-9139 & & 1.12 & 4.11 & 0.15 & & 0.31 & 0.53 \\
\hline 09-840-9175 & 3.32 & & 2.53 & & & 0.38 & 0.59 \\
\hline 09-840-9667 sub 8 & 5.48 & & 3.01 & 0.27 & & 0.01 & 0.02 \\
\hline 09-840-9672 sub 09 & 67.21 & 1.88 & 11.09 & 0.39 & & 0.02 & 0.23 \\
\hline 09-840-9673 sub 10 & 200.69 & 4.25 & 51.04 & 1.06 & 0.05 & 0.03 & 0.59 \\
\hline 09-840-9707 & 24.75 & 0.66 & 10.25 & 0.10 & & 0.29 & 1.21 \\
\hline 09-840-9858 & & & 4.99 & & & & 0.13 \\
\hline 09-840-9961 & 1.74 & & 2.54 & & & 0.16 & 0.49 \\
\hline 09-840-9962 & & & 0.61 & & & 0.19 & 0.54 \\
\hline
\end{tabular}




\section{REFERENCES}

Ankersmit, H.A., N.H. Tennent, and S.F. Watts. 2005. Hydrogen sulfide and carbonyl sulfide in the museum environment-Part 1. Atmospheric Environment, 39: 695-707.

ASTM International (2002) "Standard Test Method for Determining Formaldehyde Concentration in Air from Wood Products Using a Small Scale Chamber. Designation: D 6007-02

Baltussen, E., F. David, P. Sandra, and C. Cramers. 1999. On the performance and inertness of different materials used for the enrichment of sulfur compounds from air and gaseous samples. Journal of Chromatography A, 864: 345-350.

Bandosz, T.J. 2002. On the adsorption/oxidation of hydrogen sulfide on activated carbons at ambient temperatures. Journal of Colloid and Interface Science, 246: 1-20.

California Environmental Protection Agency (EPA), Air Resources Board (ARB). 1999. ARB Test Method 15. Determination of Hydrogen Sulfide, Carbonyl Sulfide, and Carbon Disulfide Emissions from Stationary Sources. Volume 1, Methods for Determining Compliance with District Nonvehicular (Stationary Source) Emission Standards. California ARB, Sacramento, CA, July. 12 pp. Available at: http://www.arb.ca.gov/testmeth/vol1/voll.htm. (Last accessed September 15, 2010.)

California EPA, Integrated Waste Management Board. 2003. Building material emissions study. In Section 01350, General Requirements-Special Project Procedures (Special Environmental Specifications). Sustainable (Green) Building. California EPA, Sacramento, CA. November. Available at: http://www.calrecycle.ca.gov/Greenbuilding/Specs/Section01350/METStudy.htm. (Last accessed September 21, 2010.)

Castello, G. 1999. Retention index systems: alternatives to the n-alkanes as calibration standards. Journal of Chromatography A, 842: 51-64.

CDHS (2004) California Department of Health Services "Standard Practice for the Testing of Volatile Organic Emissions from Various Sources Using Small-Scale Environmental Chambers. Environmental Health Laboratory Branch. July 15, 2004

Devai, I., and R.D. Delaune. 1996. Evaluation of various solid adsorbents for sampling trace levels of methanethiol. Organic Geochemistry, 24(8/9): 941-944.

Founie, A. Gypsum. In U.S. Geological Survey Minerals Yearbook-2003. U.S. Government Printing Office, Washington, D.C. Vol. 1: 34.1-34.10.

Goodner, K.L. 2008. Practical retention index models of $O V-101, D B-1, D B-5$, and DBWax for flavor and fragrance compounds. LWT, 41: 951-958. 
Hua, R., J. Wang, H. Kong, J. Liu, X. Lu, and G. Xu. 2004. Analysis of sulfur-containing compounds in crude oils by comprehensive two-dimensional gas chromatography with sulfur chemiluminescence detection. Journal of Separation Science, 27: 691-698.

Kim, K.-H. 2005. Some insights into the gas chromatographic determination of reduced sulfur compounds (RSCs) in air. Environmental Science \& Technology, 39: 6765-6769. [Not referenced in text-it concerns GC with PFPD]

Kim, K.-H., G.-H. Choi, Y.-J. Choi, H.-N. Song, H.-S. Yang, and J.-M. Oh. 2006a. The effects of sampling materials selection in the collection of reduced sulfur compounds in air. Talanta, 68: 1713-1719.

Kim, K.-H., E.-C. Jeon, Y.-J. Choi, and Y.-S. Koo. 2006b. The emission characteristics and the related malodor intensities of gaseous reduced sulfur compounds (RSC) in a large industrial complex. Atmospheric Environment, 40: 4478-4490.

Kovalenko, O.N., N.N. Kundo, and P.N. Kalinkin. 2001. Kinetics and mechanism of lowtemperature oxidation of $\mathrm{H}_{2} \mathrm{~S}$ with oxygen in the gas phase. Reaction Kinetics And Catalysis Letters, 72(1):139-145.

Lee, S., Q. Xu, M. Booth, T.G. Townsend, P. Chadik, and G. Bitton. Reduced Sulfur compounds in gas from construction and demolition debris landfills. Waste Management, 26: $526-533$.

Maddalena R., M. Russell, D.P. Sullivan and M.G. Apte (2009) Formaldehyde and Other Volatile Organic Chemical Emissions in Four FEMA Temporary Housing Units Environmental Science and Technology. 43:5626-5632.

McClenny, W.A., M.W. Holdren (1999) Method TO-11. Determination of Formaldehyde in Ambient Air Using Adsorbent Cartridge Followed by High Performance Liquid Chromatography (HPLC) [ActiveSampling Methodology]:. In Compendium of Methods for Determination of Toxic Organic Compounds in Ambient Air. Second Edition. Office of Research and Development, U.S. Environmental Protection Agency: Research Triangle Park, NC, 1996. EPA/625/R-96/010b

Mochalski, P., B. Wzorek, I. Śliwka, and A. Amann. 2009. Suitability of different polymer bags for storage of volatile sulphur compounds relevant to breath analysis. Journal of Chromatography B, 877: 189-196.

Ni, J.-Q., A.J. Heber, C.A. Diehl, and T.T. Lim. 2000. Ammonia, hydrogen sulphide, and carbon dioxide release from pig manure in under-floor deep pits. Journal of Agricultural Engineering Research, 77(1): 53-66.

Pal, R., K.-H. Kim, E.-C. Jeon, S.-K. Song, Z.-H. Shon, S.-Y. Park, K.-H. Lee, S.-J. Hwang, J.-M. Oh, and Y.-S. Koo. 2009. Reduced sulfur compounds in ambient air 
surrounding an industrial region in Korea. Environmental Monitoring and Assessment, 148:109-125.

Pandey, S.K., and K.-H. Kim. 2009. A review of methods for determination of reduced sulfur compounds (RSCs) in air. Environmental Science \& Technology, 43: 3020-3029.

Parthasarathy, S., Maddalena, R.; Russell, M.; Apte, M.G. 2010 Effect of temperature and humidity on formaldehyde emissions in temporary housing units. Report LBNL- 3547E..

Ras, M.R., F. Borrull, and R.M. Marcé. 2008a. Determination of volatile organic sulfur compounds in the air at sewage management areas by thermal desorption and gas chromatography-mass spectrometry. Talanta, 74: 562-569.

Ras, M.R., R.M. Marcé, and F. Borrull. 2008b. Solid-phase microextraction-gas chromatography to determine volatile organic sulfur compounds in the air at sewage treatment plants. Talanta, 77:774-778.

Restek. 2005. Sulfinert-treated sample cylinders. By N. Mosesman. Restek Chromatography Products, Bellefonte, PA. Vol. 4, p. 12.

Shirey, R. 1997. SPME/GC analyses of sulfur gases and VOCs using a new Carboxen/PDMS filter. Supelco. 16(1): 7. Reprint available at: http://www.sigmaaldrich.com/etc/medialib/docs/Supelco/The Reporter/7695.Par.0001.Fi le.tmp/7695.pdf. (Last accessed September 15, 2010.)

Sigma-Aldrich Corporation. 1998. Supelco Bulletin 923: Solid Phase Microextraction: Theory and Optimization of Conditions. Sigma-Aldrich Corporation, St. Louis, MO. 9 pp. Available at:

http://www.sigmaaldrich.com/etc/medialib/docs/Supelco/Bulletin/4547.Par.0001.File.tmp 14547.pdf. (Last accessed September 15, 2010.)

SilcoTek. 2009. SilcoNert2000: deactivated sampling and transfer system components. SilcoTek, Bellefonte, PA. 2 p. Described at: http://www.silcotek.com/SilcoNert-inertcoating. (Last accessed September 15, 2010

Trabue, S., K. Scoggin, F. Mitloehner, H. Li, R. Burns, and H. Xin. 2008. Field sampling method for quantifying volatile sulfur compounds from animal feeding operations. Atmospheric Environment, 42: 3332-3341.

Van Netten, C., Shirtliffe, C., Svec, J. 1989 Temperature and humidity dependence of formaldehyde release from selected building materials. Bulletin of Environmental Contamination and Toxicology., 42, pp 558-565.

Yan, X. 2006. Unique selective detectors for gas chromatography: nitrogen and sulfur chemiluminescence detectors. Journal of Separation Science, 29: 1931-1945. 
Zhang, Z., Luo, X., Wang, X., Q, K., Zhao, R. 2007 Influence of temperature on formaldehyde emission parameters of dry building materials. Atmospheric Environment., 41, pp 3203-3216. 